\title{
Uncertainty of lateral boundary conditions in a convection-permitting ensemble: a strategy of selection for Mediterranean heavy precipitation events
}

\author{
O. Nuissier, B. Joly, B. Vié, and V. Ducrocq \\ GAME/CNRM, Météo-France, URA1357, CNRS, Toulouse, France \\ Correspondence to: O. Nuissier (olivier.nuissier@meteo.fr)
}

Received: 28 February 2012 - Revised: 29 June 2012 - Accepted: 28 August 2012 - Published: 1 October 2012

\begin{abstract}
This study examines the impact of lateral boundary conditions (LBCs) in convection-permitting (C-P) ensemble simulations with the AROME model driven by the ARPEGE EPS (PEARP). Particular attention is paid to two torrential rainfall episodes, observed on 15-16 June 2010 (the Var case) and 7-8 September 2010 (the Gard-Ardèche case) over the southeastern part of France. Regarding the substantial computing time for convection-permitting models, a methodology of selection of a few LBCs, dedicated for C-P ensemble simulations of heavy precipitation events is evaluated. Several sensitivity experiments are carried out to evaluate the skill of the AROME ensembles, using different approaches for selection of the driving PEARP members. The convective-scale predictability of the Var case is very low and it is driven primarily by a surface low over the Gulf of Lyon inducing a strong convergent low-level flow, and accordingly advecting strong moisture supply from the Mediterranean Sea toward the flooded area. The Gard-Ardèche case is better handled in ensemble simulations as a surface cold front moved slowly eastwards while increasing the low-level water vapour ahead is well reproduced. The selection based on a cluster analysis of the PEARP members generally better performs against a random selection. The consideration of relevant meteorological parameters for the convective events of interest (i.e. geopotential height at $500 \mathrm{hPa}$ and horizontal moisture flux at $925 \mathrm{hPa}$ ) refined the cluster analysis. It also helps in better capturing the forecast uncertainty variability which is spatially more localized at the "high-impact region" due to the selection of more mesoscale parameters.
\end{abstract}

\section{Introduction}

The northwestern Mediterranean area is frequently affected by heavy precipitation events (HPEs) that produce disastrous flash-flood events, particularly during autumn. In most cases of dramatic events, large amounts of precipitation are recorded in less than one day (typically more than $200 \mathrm{~mm}$ in less than $24 \mathrm{~h}$, and sometimes in only $6 \mathrm{~h}$ ) when a mesoscale convective system (MCS) develops and stays over the same area for several hours.

The ability to predict such dramatic events remains weak due to the contribution of very fine-scale processes over the northwestern Mediterranean complex terrain and their non-linear interactions with the larger scale processes. The knowledge of the large-scale meteorological environment propitious to heavy precipitation has been increased for past years. Despite a better prediction of these precursors, the forecast of the precise location of the anchoring region of the precipitating system, especially in case of extreme event, is nowadays still a challenging issue. Furthermore, a better knowledge of the forecast uncertainty is really crucial as the hydrological response of the typical small and steep Mediterranean watersheds is very sensitive to the location of the heaviest precipitation (Chancibault et al., 2006; Vincendon et al., 2010).

The recent studies by Nuissier et al. $(2008,2011)$ showed typical upper-level synoptic ingredients such as the deep cyclonic upper-level circulation that generates a strong diffluent flow over the Mediterranean Sea and a blocking located downstream over central Europe slowing down the evolution of these synoptic conditions. These synoptic patterns are generally associated with intense south to southeasterly low-level jets that favour strong low-level moisture transport 
towards the flooded areas. In addition, mesoscale ingredients are also crucial in the triggering of deep convection (e.g. conditional instability, low-level convergence, moisture flux), pinpointing the deep convection development over the same area over several hours.

A new generation of non-hydrostatic convectionpermitting (C-P) atmospheric models have been developed in the past years for operational or research purposes. The forecast of precipitation systems is significantly improved with these new-generation models due to a better representation of water cycle processes and resolved deep convection (Stein et al., 2000; Mass et al., 2002; Richard et al., 2003; Fritsch and Carbone, 2004; Ducrocq et al., 2008; Bresson et al., 2009; Bresson, 2011, among others). However, more faithful simulations do not imply systematic increased quality (e.g. in terms of quantitative precipitation forecasts) of model forecasts as measured by "grid-based" metrics (Mass et al., 2002). Convective processes are highly nonlinear and associated with very short lifespans. As a consequence, their forecasts are strongly impacted by uncertainties, e.g. emerging from the initial state of the model, from the formulation of the model and from the lateral boundary conditions which are provided by the driving model, in case of limited area models (Gebhardt et al., 2011). This meteorological uncertainty can then propagate to the hydrological forecasts, since hydrological forecasts are strongly related to precipitation forecasts (Zappa et al., 2010).

Ensemble forecasting or ensemble simulation approaches are well known tools to quantify the forecast uncertainty. Such a probabilistic methodology, thanks to available computing resources, has been introduced for operational purposes in the 1990s, using Ensemble Prediction Systems (EPSs) designed for medium-range forecasting (Molteni and Palmer, 1993; Molteni et al., 1996; Toth and Kalnay, 1997). Unfortunately, these methods designed to generate a global, large-scale ensemble cannot be easily adapted to C-P numerical weather prediction models due to strong nonlinearities and large sensitivity to initial conditions.

Recent studies make use of a wide range of techniques to build ensemble forecasts at meso- $\beta$ for regional, limitedarea, convection-parameterizing (or not) models (Stensrud et al., 2000; Grimit and Mass, 2002; Nutter et al., 2004; Walser et al., 2004; Zhang et al., 2006; Hohenegger et al., 2006; Hohenegger and Schär, 2007; Kong et al., 2007, among others). For very high (e.g. kilometric)-resolution, Vié et al. (2011) examines the impact of uncertainty on convective-scale initial conditions and the uncertainty on lateral boundary conditions (LBCs) in cloud-resolving simulation with the Application of Research to Operations at Mesoscale (AROME) model at 2.5-km horizontal resolution, with special attention paid to Mediterranean heavy precipitation. They show that the uncertainty of LBC has an impact at longer range than uncertainty of mesoscale initial conditions (typically beyond $12 \mathrm{~h}$ ), as the spread in the driving global
EPS increases. Moreover, the rate of LBC uncertainty propagation depends on the synoptic-scale meteorological conditions. Gebhardt et al. (2011) explore the use of perturbation methods within the COSMO-DE model at 2.8-km horizontal resolution, isolating uncertainty sources (e.g. model errors and LBCs). They obtain results fairly similar to Vié et al. (2011), with model perturbations always dominating the first few hours and variations of LBCs often dominating the following forecast hours.

The studies mentioned above have shown the importance of using global large-scale EPS as perturbed LBCs for C$P$ EPS. Furthermore, the design of a future C-P EPS will need to tackle the major uncertainty sources previously mentioned. At first glance, the approach would basically combine $N$ global EPS members as driving LBCs and $M$ other members representing additional perturbations generated in the CP model, thus involving the computation of $N \times M$ members in that configuration. Despite significant increase of computational power, a major issue for convective-scale EPS is the size of the ensemble since C-P models suffer from expansive computing time. Whereas large-scale global EPS size is typically $35-50$ members, $8-15$ members in C-P EPS can be the targeted size for operational implementation. A selection among the large-scale EPS members should thus be applied to drive the C-P EPS. It is based on a selection of a few representative members from global EPSs, followed by nesting of limited-area models with the retained individual large-scale solutions. The Consortium for Small-Scale MOdelling Limited-area Ensemble Prediction System (COSMOLEPS), for instance, already uses such a methodology (Marsigli et al., 2001; Molteni et al., 2001; Montani et al., 2011) but for a convection-parameterizing model.

The present work aims at addressing whether such an approach is relevant for a C-P EPS working at kilometric horizontal resolution and for short-range lead times (up to $24 \mathrm{~h}$ ). Therefore, this paper proposes to evaluate a methodology of selection of LBCs dedicated for C-P ensemble simulations of heavy precipitation events. For that purpose, several C-P ensemble simulation experiments are carried out, with various subsets of LBCs provided by a short-range global EPS. In this approach, the C-P model is assumed to be "perfect" and that the major uncertainty sources are mainly associated with variability of the meteorological synoptic-scale patterns propagating inside the C-P numerical model.

The paper is organised as follows: Sect. 2 reports the meteorological description of the case studies. The numerical experiments set up and the methodology used are described in Sect. 3, results are presented then discussed in Sect. 4. Finally, a synthesis and concluding remarks are given in Sect. 5 . 


\section{The case studies}

Our study focuses on two recent flash-flooding events: 1516 June 2010 (called hereafter the Var case) and 7-8 September 2010 (called hereafter the Gard-Ardèche case). The Gard-Ardèche case occurred over the southeastern region of Massif Central which is a typical area for very heavy precipitation from climatology. On the other hand, the Var case was an exceptional episode since it occurred in June (autumn is the favourable period) and over a region usually less exposed to heavy precipitation (southern flanks of the Alps).

\subsection{The Var case}

Figure 1a illustrates the synoptic situation associated with the Var case in terms of the $500 \mathrm{hPa}$ geopotential height, $1.5 \mathrm{PVU}$ surface height, $300 \mathrm{hPa}$ wind fields, $925 \mathrm{hPa}$ adiabatic wetbulb potential temperature and wind fields (derived from the ARPEGE analysis) on 15 June 2010 at 12:00 UTC. The meteorological situation was dominated by an upper-level (almost cut-off) cold low centred through the Northern Iberian peninsula and the Bay of Biscay. The main upper-level PV anomaly, shown by low elevation of the 1.5 PVU (potential vorticity unit) surface, extending southwestwards and was associated with a pronounced mid to upper-level southerly flow (Fig. 1a). In the same time at low-level, a large surface low deepened between Balearic Islands and Sardinia and led to a moderate and moist south to southeasterly low-level flow impinging upon the southern Alps foothills (Fig. 1b). This low-level circulation in addition to flow deflection around Southern Alps helped in reinforcing low-level convergence and focusing moist air masses, with high values of adiabatic wet-bulb potential temperature, towards the flooded-area (i.e. the Var region). These very favourable conditions for heavy precipitation, rather atypical for the season, lasted the entire day on 15 June.

The first convective cells associated with the Var event appeared over the Mediterranean Sea around 00:00 UTC on 15 June 2010, embedded in the southerly low-level flow. Progressing northwards, the convection started to organise forming a very intense south-north oriented line in the morning on 15 June (Fig. 2a). The convective line turned more southeastnorthwest in the afternoon associated with a more easterly shift of the low-level flow (Fig. 2b). During the Var event, high surface rainfall amounts of about $460 \mathrm{~mm}$ in less than $24 \mathrm{~h}$ were recorded in Draguignan which in large part can be directly attributed to this stationary convective line (Fig. 2c). This event led to dramatic flash-flooding that caused the deaths of 25 people and considerable damages.

\subsection{The Gard-Ardèche case}

As for the Var case, the upper-level synoptic situation is presented in Fig. 3a at 12:00 UTC on 7 September 2010. The synoptic-scale situation was characterised by a large upper-
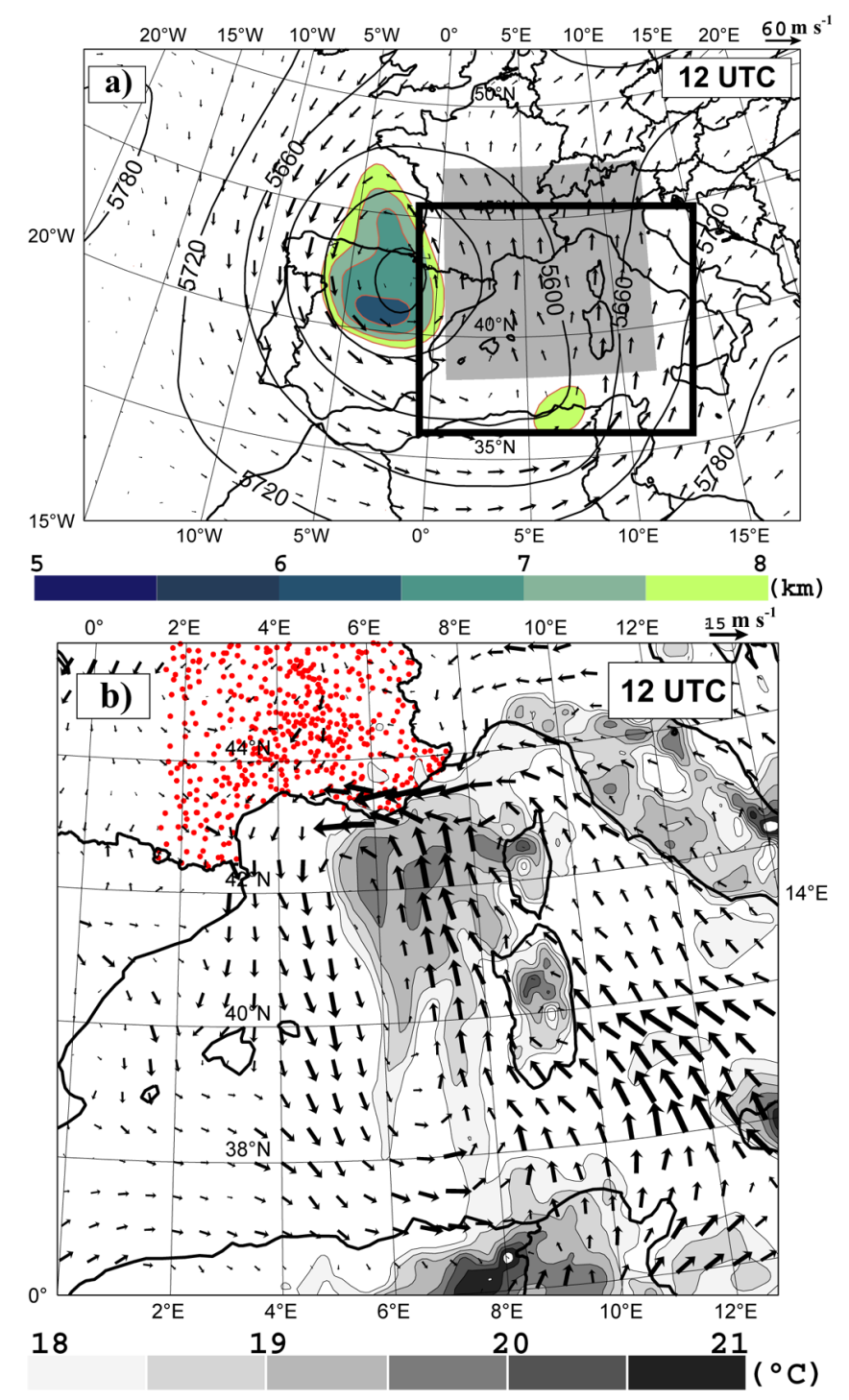

Fig. 1. Var case (a): $300 \mathrm{hPa}$ winds (arrows), 1.5 PVU surface height (colour) and $500 \mathrm{hPa}$ geopotential height (solid line) and (b): adiabatic wet-bulb potential temperature (shading) and horizontal winds at $925 \mathrm{hPa}$, from ARPEGE analysis on 15 June 2010 at 12:00 UTC. The computational domain (shading) used for AROME ensemble simulations is shown in (a). The black rectangle represents the domain seen in (b).

level cold low located away from France (i.e. near $5^{\circ} \mathrm{W}$ ) moving gradually eastward, and by a mid- to upper-level ridge centred over Northern Italy (Fig. 3a). Between these two large-scale structures prevailed a fairly strong upperlevel southwesterly flow over the southeastern regions of France. The analysis of low-level conditions (Fig. 3b) clearly depicts a strong south to southwesterly low-level jet, emerging from the Balearic Islands with high values of adiabatic wet-bulb potential temperature, bringing and focusing very moist and unstable air masses to the Massif Central foothills. 

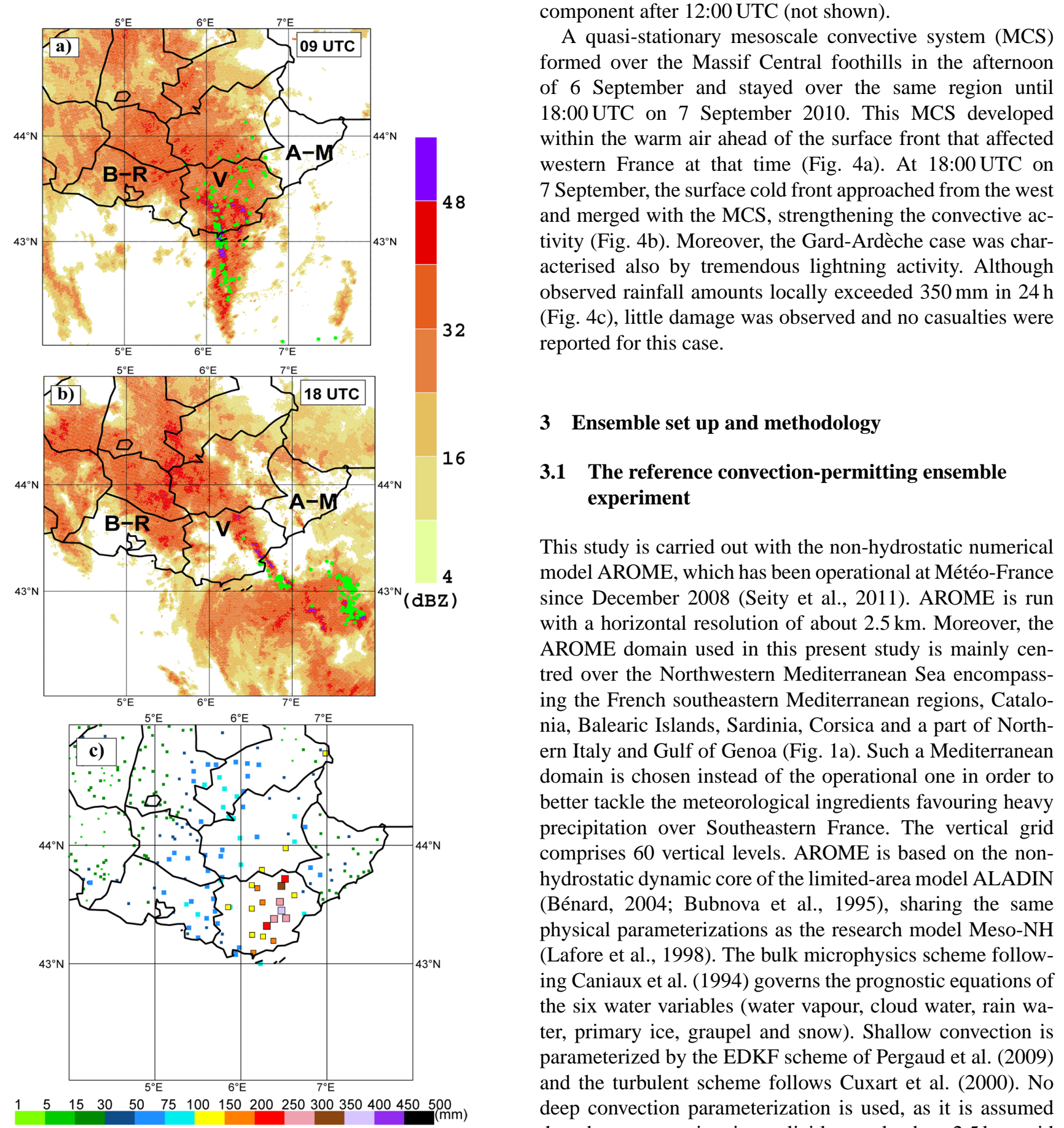

Fig. 2. Var case radar reflectivities composite from the observations on 15 June 2010 at (a) 09:00 UTC, and (d) 18:00 UTC, respectively. The green squares show lightning strikes observed during $3 \mathrm{~h}$ from the radar time. The thin lines delineate the departments (administrative areas of France); the Bouches du Rhônes, the Var and the AlpesMaritime departments are labelled B-R, V, and A-M, respectively. (c) stands for rainfall observations from 06:00 UTC, 15 June 2010 to 06:00 UTC, 16 June 2010.
This south to southwesterly low-level jet took a more easterly component after 12:00 UTC (not shown).

A quasi-stationary mesoscale convective system (MCS) 18:00 UTC on 7 September 2010. This MCS developed within the warm air ahead of the surface front that affected 7 September, the suface cold fiont approached from the west and merged with the MCS, strengthening the convective activity (Fig. 4b). Moreover, the Gard-Ardèche case was characterised also by tremendous lightning activity. Although observed rainfall amounts locally exceeded $350 \mathrm{~mm}$ in $24 \mathrm{~h}$ reported for this case.

\section{Ensemble set up and methodology}

\subsection{The reference convection-permitting ensemble experiment}

This study is carried out with the non-hydrostatic numerical model AROME, which has been operational at Météo-France since December 2008 (Seity et al., 2011). AROME is run with a horizontal resolution of about $2.5 \mathrm{~km}$. Moreover, the AROME domain used in this present study is mainly centred over the Northwestern Mediterranean Sea encompassing the French southeastern Mediterranean regions, Catalonia, Balearic Islands, Sardinia, Corsica and a part of Northern Italy and Gulf of Genoa (Fig. 1a). Such a Mediterranean domain is chosen instead of the operational one in order to better tackle the meteorological ingredients favouring heavy precipitation over Southeastern France. The vertical grid comprises 60 vertical levels. AROME is based on the nonhydrostatic dynamic core of the limited-area model ALADIN (Bénard, 2004; Bubnova et al., 1995), sharing the same physical parameterizations as the research model Meso-NH (Lafore et al., 1998). The bulk microphysics scheme following Caniaux et al. (1994) governs the prognostic equations of the six water variables (water vapour, cloud water, rain water, primary ice, graupel and snow). Shallow convection is parameterized by the EDKF scheme of Pergaud et al. (2009) and the turbulent scheme follows Cuxart et al. (2000). No deep convection parameterization is used, as it is assumed that deep convection is explicitly resolved at $2.5 \mathrm{~km}$ grid spacing.

AROME uses LBCs interpolated from ARPEGE forecasts (about $10 \mathrm{~km}$ horizontal resolution over France), with a coupling frequency of $1 \mathrm{~h}$. The AROME data assimilation system uses a rapid forward sequential assimilation cycle with a 3-hourly data analysis frequency. The observations assimilated in the 3-D-VAR AROME system included those from radio soundings, screen-level stations, wind profilers, GPS, buoys, ships, and aircraft. Assimilated satellite data 

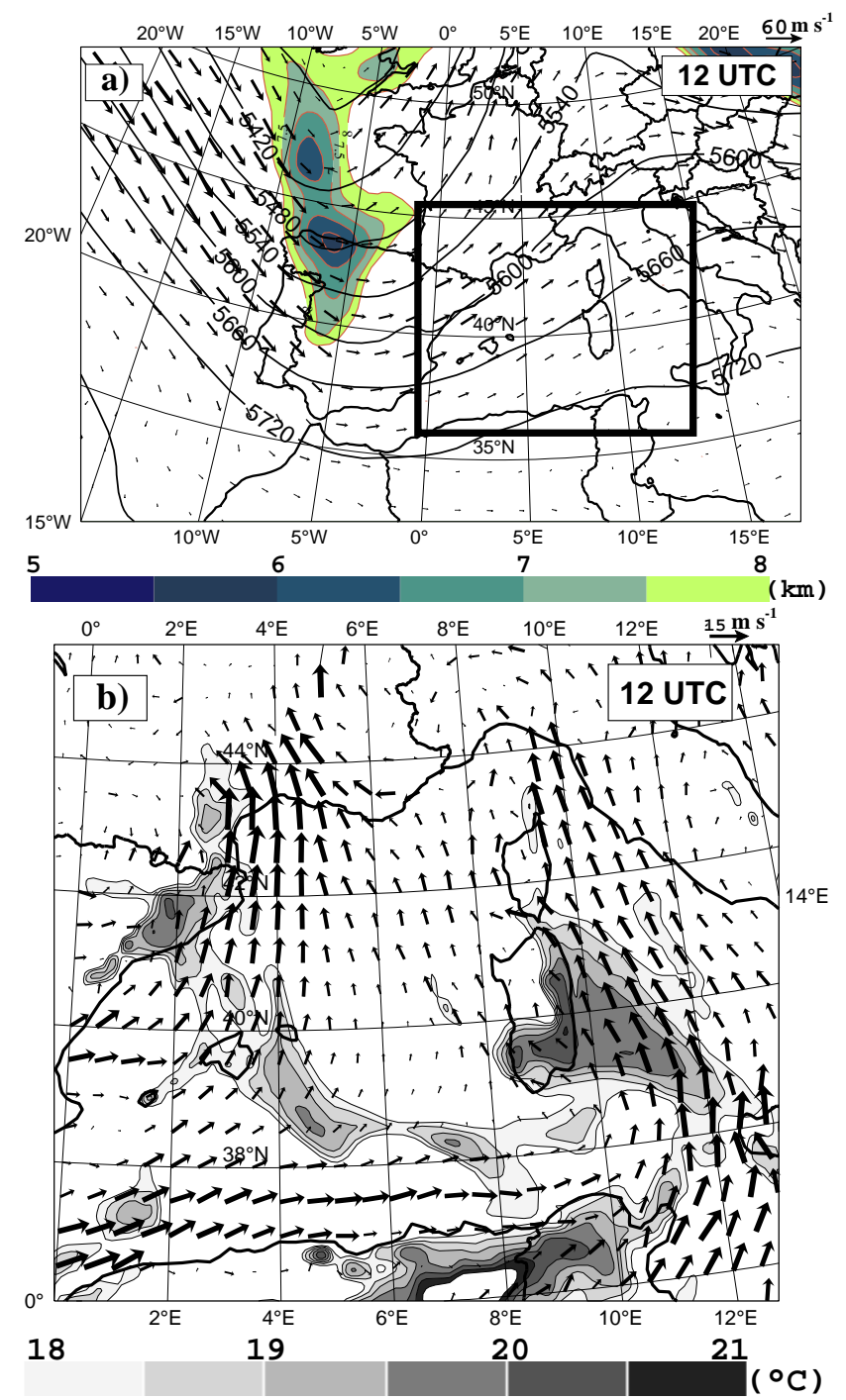

Fig. 3. Gard case (a): $300 \mathrm{hPa}$ winds (arrows), $1.5 \mathrm{PVU}$ surface height (colour) and $500 \mathrm{hPa}$ geopotential height (solid line) and (b): adiabatic wet-bulb potentail temperature (shading) and horizontal winds at $925 \mathrm{hPa}$, from ARPEGE analysis on 7 September 2010 at 12:00 UTC. The black rectangle represents the domain seen in (b).

included horizontal winds from atmospheric motion vectors (AMVs) and the QuickSCAT scatterometers, Advanced Microwave Sounding Unit (AMSU)-A and -B radiances from the NOAA-15, -16, -17, and the Aqua satellites, Highresolution Infrared Sounder (HIRS) radiances from NOAA17, and clear-air Spinning Enhanced Visible and Infrared Imager (SEVIRI) radiances from the Meteosat- 8 satellite. In addition, AROME assimilates Doppler radial winds from the weather radar network over France.

To carry out the C-P ensemble experiments, AROME is driven by the global short-range ARPEGE EPS (called hereafter PEARP). PEARP uses a stretched horizontal grid over the globe, allowing higher horizontal resolution over West-
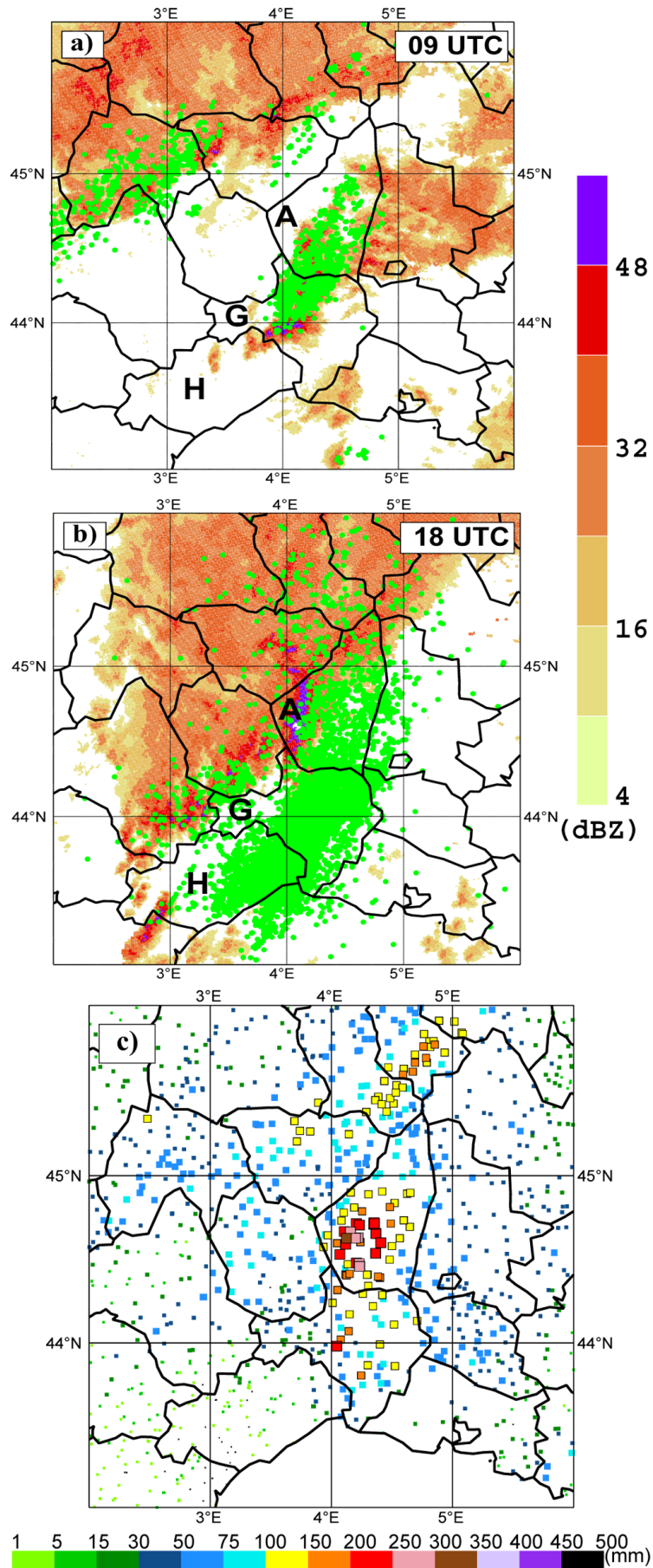

Fig. 4. Gard case radar reflectivities composite from the observations on 7 September 2010 at (a) 09:00 UTC, and (d) 18:00 UTC, respectively. The green squares show lightning strikes observed during $3 \mathrm{~h}$ from the radar time. The thin lines delineate the departments (administrative areas of France); the Bouches du Rhônes, the Var and the Alpes-Maritime departments are labelled B-R, V, and A-M, respectively. (c) stands for rainfall observations from 06:00 UTC, 7 September 2010 to 06:00 UTC, 8 September 2010. 
ern Europe. The control run is similar to the ARPEGE operational deterministic system, except for it coarser grid spacing of about $15 \mathrm{~km}$ over France. The initial conditions for the other 34 members are obtained by adding perturbations to the control run. The perturbation method blends ensemble assimilation in ARPEGE and calculation of 12-h dry singular vectors.

A first reference ensemble simulation (called hereafter REF) is performed to analyse the convective-scale predictability of both case studies. The REF ensemble experiment used in this study has 35 members (i.e. 34 perturbed +1 control member) and is driven by the PEARP members which also counts 35 members. In order to get the best as possible mesoscale initial state for our C-P ensemble and simultaneously examine the impact of LBC uncertainty, all members start from a unique initial condition provided by a parallel mesoscale data assimilation performed over the AROME domain. This mesoscale data assimilation cycle starts two days before the time of the events, that means on 13 June 2010 at 00:00 UTC for the Var case and on 5 September 2010 at 00:00 UTC for the Gard-Ardèche case, respectively.

\subsection{A dedicated cluster analysis for heavy precipitation events}

The approach adopted in this study lies in the idea of reducing the number of global-ensemble members driving the limited-area forecasts, still retaining a large fraction of the driving-ensemble variability. The selection technique used here consists of a dynamical clustering of the largescale meteorological circulation patterns simulated by the 35 PEARP's members.

Based on the knowledge of the large and subsynoptic-scale environment patterns favourable to intense precipitation in the Mediterranean area (Nuissier et al., 2011), specific statistical predictors are precisely used to refine the dynamical clustering. The methodology is the following:

i. a PEARP ensemble run, starting on given day at 00:00 UTC, is first considered. Here two forecast times are considered $t+9 \mathrm{~h}$ and $t+30 \mathrm{~h}$.

ii. for each PEARP member, specific meteorological parameters are extracted over a large Mediterranean domain at different levels and for various time steps,

iii. a $\left(\mathrm{N}_{v} \times \mathrm{N}_{p}\right)$ matrix is then built where $\mathrm{N}_{p}$ is the number of members and $\mathrm{N}_{v}$ is the number of parameters times the number of levels times the number of grid points times the number of forecast steps. Each variable of the matrix (i.e. column) $v_{i}$ is normalised regarding to the mean and the standard deviation of all members $p_{i}$.

iv. a cluster analysis is performed over Southern Europe (approximately $60^{\circ} \mathrm{N}-30^{\circ} \mathrm{N}, 10^{\circ} \mathrm{W}-40^{\circ} \mathrm{E}$ ) and the complete-linkage algorithm, through a hierarchical cluster analysis, is used to construct the clusters.

v. the representative member (RM), chosen among each cluster, is the nearest element from its respective centroid and simultaneously the more distant from the other centroids. The above RMs provide both initial conditions and LBCs for the AROME model.

\subsection{The convection-permitting ensemble simulations}

To evaluate the impact of an "oriented" LBC selection against a random approach, and to assess the sensitivity of clustering to specific meteorological parameters favourable for heavy precipitation, 4 ensemble simulation experiments are carried out, in which LBCs for AROME are selected from PEARP members. The initial size of the reference ensemble is reduced down to 8 members in two experiments, either randomly selecting 7 LBCs from PEARP members (called hereafter $R A N D 1, R A N D 2$ ) or isolating 7 LBCs from a cluster analysis on PEARP members (called hereafter CLUST$R E F$ and CLUST-MOIST). RANDI is a first set of 7 LBCs by drawing lots among 34 and $R A N D 2$ is a second set. For each type of sub-ensemble, the control member is the same as in the one in the reference one. The choice of size of 8 members for our ensembles is purely subjective and corresponds to the targeted ensemble size expected for the design of the future AROME C-P EPS.

In CLUST-REF, the methodology for the dynamical clustering closely follows the one adapted for COSMO-LEPS (Molteni et al., 2001; Marsigli et al., 2001; Montani et al., 2003; Marsigli et al., 2005; Federico et al., 2007; Montani et al., 2011). The meteorological parameters are the geopotential height $Z$, the two horizontal wind components $U$ and $V$, and the specific humidity $Q$ all at 850,700 and $500 \mathrm{hPa}$, respectively. In CLUST-MOIST, the dynamical core of the clustering is the same as in CLUST-REF, except that specific statistical predictors for heavy precipitation over the region (e.g. geopotential at $500 \mathrm{hPa}$ and the moisture flux at $925 \mathrm{hPa}$ ) are only considered in the clustering.

Finally, a last series of ensemble simulations is considered to evaluate the added value of joining successive PEARP runs for the dynamical clustering. The use of this superensemble was introduced by Montani et al. (2003) and Marsigli et al. (2005), aiming at increasing the spread of the global ensemble on which the cluster analysis is performed. For that purpose, the $L A G$ ensemble is driven by a set of PEARP members starting either at the forecast start time or $12 \mathrm{~h}$ before. It is worth noticing that all ensemble simulations are run for $30 \mathrm{~h}$, starting at 00:00 UTC on 15 June 2010 or at 00:00 UTC on 7 September 2010. 

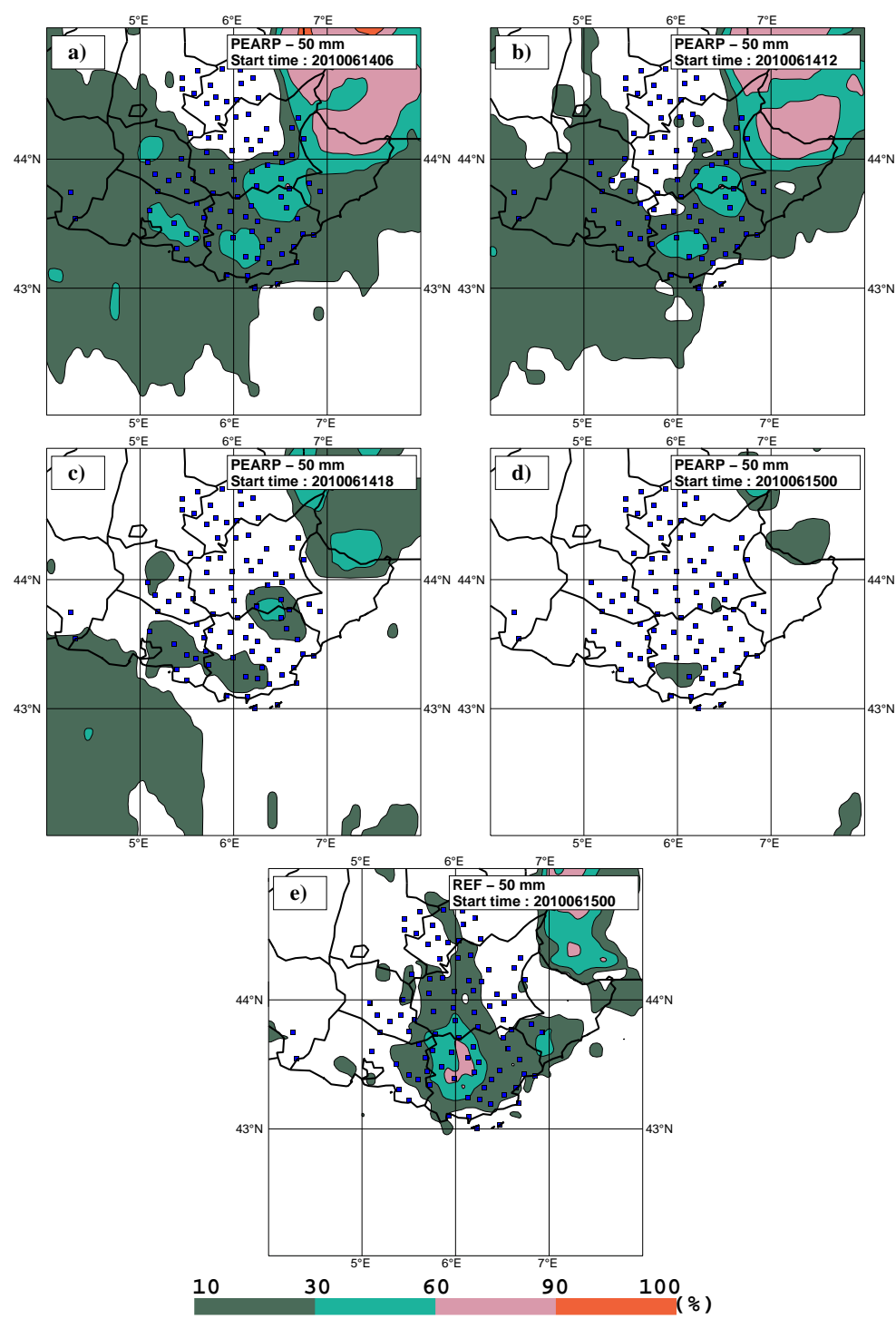

Fig. 5. Var case probability map for the 24-h accumulated precipitation (valid at 06:00 UTC on 16 June 2010) exceeding $50 \mathrm{~mm}$ and for the PEARP ensemble starting at: (a) 06:00 UTC, 14 June 2010, (b) 12:00 UTC, 14 June 2010, (c) 18:00 UTC, 14 June 2010 and (d) 00:00 UTC, 15 June 2010. (e) and (f) stand for the REF convective-permitting ensemble experiment starting at 00:00 UTC, 15 June 2010 and for the thresholds 50 and $100 \mathrm{~mm}$. The squares are observations (rain-gauges) over the same threshold.

\section{Overall performance of ensembles}

This section compares the performance of the reference C$\mathrm{P}$ ensemble (i.e. REF) and the skill of the driving lowerresolution PEARP in terms of quantitative precipitation forecasts (QPFs). In order to facilitate the direct comparison between PEARP and REF, the grid point forecasts of both ensembles are aggregated over boxes of $0.2 \times 0.2^{\circ}$, averaging all the forecast values falling into the boxes. We focus primarily on the phases of heavy precipitation occurring between 15 and 16 June 2010 over southern foothills of Alps, and between 6 and 7 September 2010 over the southeastern region of the Massif Central (see Sect. 2), adopting an uniform presentation for both cases.

\subsection{The Var case}

The probabilistic forecasts from PEARP are presented for the Var case in Fig. 5a, b, c and d and for different starting times. The panels show the probability maps for precipitation forecasts exceeding $50 \mathrm{~mm} \mathrm{day}^{-1}$, valid for 16 June 2010 at 06:00 UTC and starting at 00:00 UTC on 15 June 2010 and at 18:00, 12:00 and 06:00 UTC on 14 June 2010. Unexpectedly, high values of probability are not obtained for the nearest time of the event, but for the longest forecast ranges. 

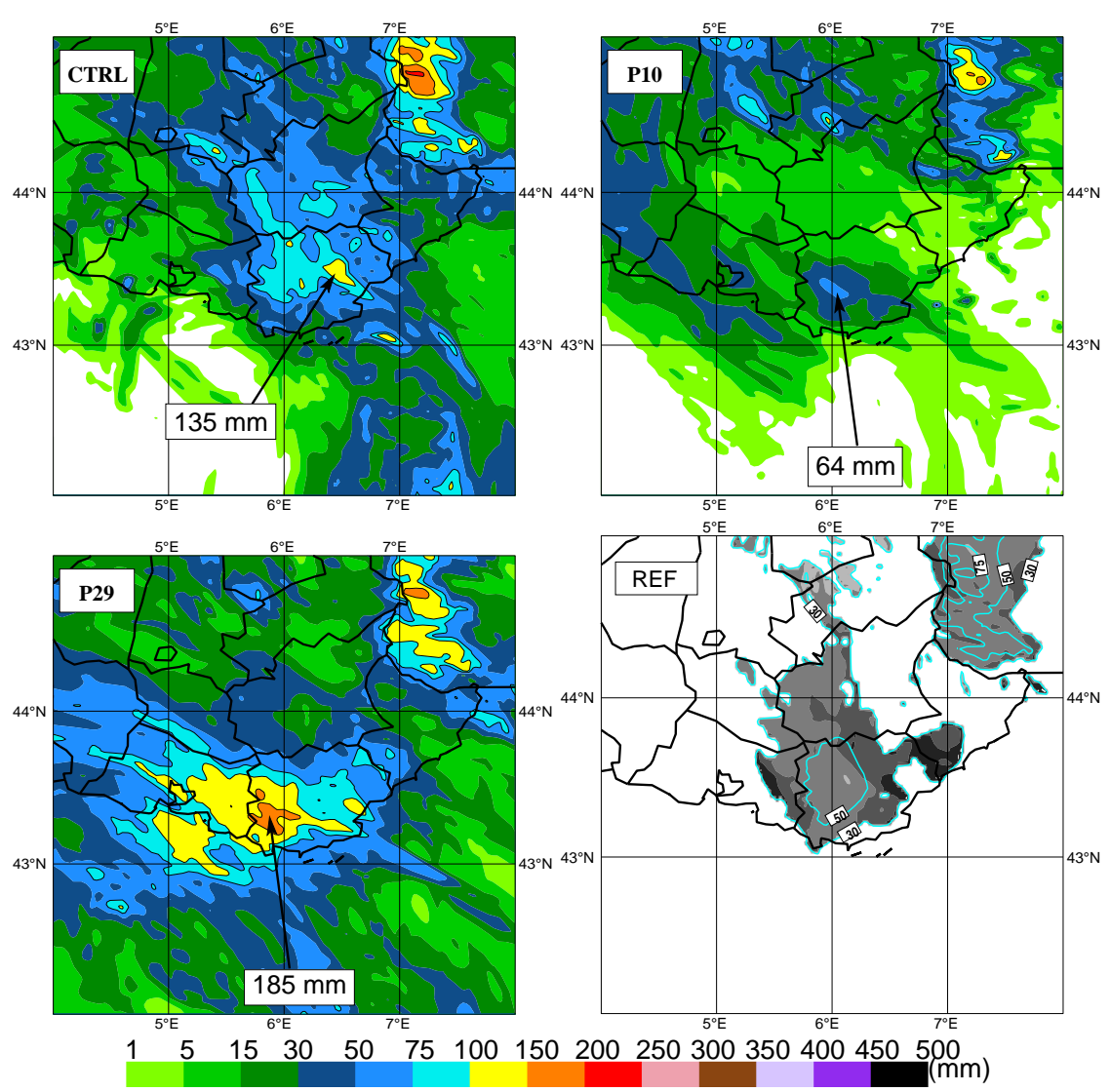

Fig. 6. Var case 24-h accumulated simulated precipitation for the REF convective-permitting ensemble experiment. The run is valid for 16 June 2010 at 06:00 UTC and starts on 15 June 2010 at 00:00 UTC. Precipitation maxima are pointed out over the Var department. The last panel shows the 24-h accumulated ensemble-mean (solid line) and the normalised spread (shading). The spread is not shown for precipitation below $30 \mathrm{~mm}$ day $^{-1}$.

Indeed, the highest probability are located over Italy with two areas of about $70 \%$ and $40 \%$ over the northeastern and southwestern portion of the Var Department on 14 June 2010 at 06:00 UTC (Fig. 5a). The Var region still have significant probabilities of heavy precipitation regarding forecasts starting at 12:00 UTC on 14 June 2010, but the values strongly decrease beyond 18:00 UTC and especially for the run starting at 00:00 UTC on 15 June 2010 (Fig. 5d). Therefore, an important result for the Var case is that the best skill is not obtained for the most recent PEARP ensemble forecasts. The "oldest" runs better predict the favourable synoptic-scale meteorological ingredients. For instance, the PEARP run starting at 12:00 UTC on 14 June 2010 depicts on average more members with a stronger upper-level PV- anomaly closer to the flooded area, providing a more pronounced southerly upper-level flow over the flooded area (not shown).

Figure $5 \mathrm{e}$ displays the same probability maps shown for PEARP but for the REF experiment and for the thresholds $50 \mathrm{~mm}$, respectively. One can remark that the REF experiment yields substantial improved QPFs. Although the areas affected by heavy precipitation are misplaced westward, the
REF ensemble simulation enables to focus and clearly isolate the heaviest precipitation amount probability over the flooded area (Fig. 5e).

Accumulated precipitation for the control and the better/worse members of REF are shown in Fig. 6. There are obvious differences and a strong variability between members, in terms of location as well as in intensity. A local maximum over the Var region of about $64 \mathrm{~mm}$ in $24 \mathrm{~h}$ is simulated by member 10 (worse), whereas $185 \mathrm{~mm}$ is obtained by member 29 (better). The precipitation forecasts of some members are very accurate, but no member predicts precipitation peaks of about $460 \mathrm{~mm}$ as observations (Fig. 6 vs. Fig. 2c). This could be due to the lack or bad representation of some very favourable ingredients (i.e. low-level moisture convergence), triggering deep convection over Mediterranean Sea.

As in Hohenegger et al. (2006), we pay attention to the assessment of the predictability for our case studies. For that purpose, the ensemble spread is used as a measure with large spread indicating poor predictability and vice versa. The spread-skill relation, i.e. more (less) spread leads to less (higher) predictability, is well established for the prediction 

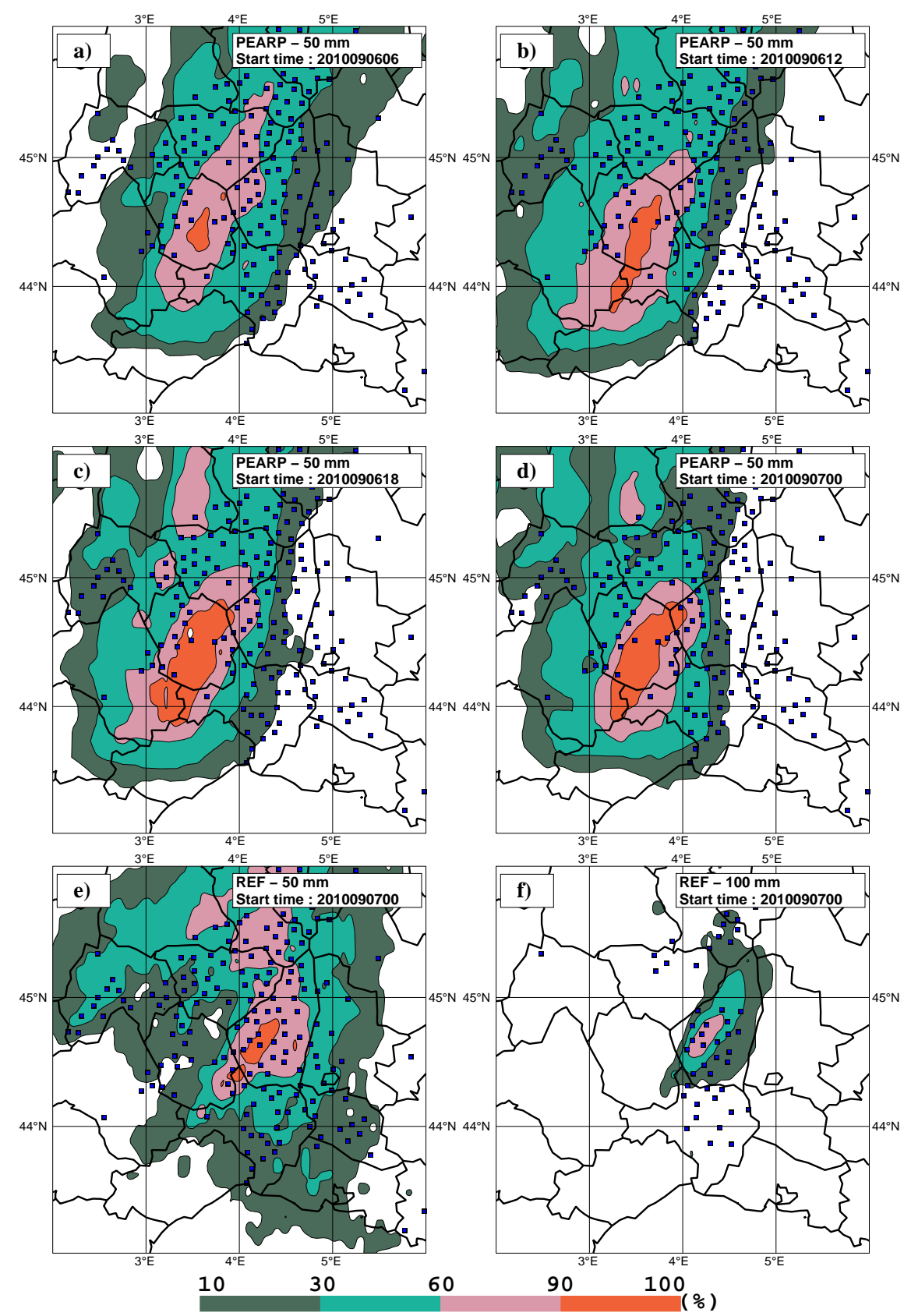

Fig. 7. Gard case probability map for the 24-h accumulated precipitation (valid at 06:00 UTC on 8 September 2010) exceeding 50 mm and for the PEARP ensemble starting at: (a) 06:00 UTC, 6 September 2010, (b) 12:00 UTC, 6 September 2010, (c) 18:00 UTC, 6 September 2010 and (d) 00:00 UTC, 7 September 2010. (e) and (f) stand for the REF convective-permitting ensemble experiment starting at 00:00 UTC, 7 September 2010 and for the thresholds 50 and $100 \mathrm{~mm}$. The squares are observations (rain-gauges) over the same threshold.

of upper-air variables in the framework of global-ensemble forecasting. Although this relation is less clear as for prediction of surface fields (as some topographic effects could affect predictability), surface precipitation spread is used as a measure of predictability. The spread $S$ is calculated as the standard deviation for the precipitation parameter $P$, i.e. $S=\sqrt{\frac{1}{N-1} \sum_{i=1}^{N}\left(P_{i}-\bar{P}\right)^{2}}$, where $N$ denotes the num- ber of ensemble members and $\bar{P}$ is the precipitation ensemble mean. Since precipitation fields can display strong variability, a normalised spread defined as $S \times \bar{P}^{-1}$ is used. It is worth noticing that this normalised spread is rather useful, where precipitation amounts are strong but may lead to unrealistically large spread values especially at the borders of rainy areas. The last panel of Fig. 6 illustrates the 24-h 

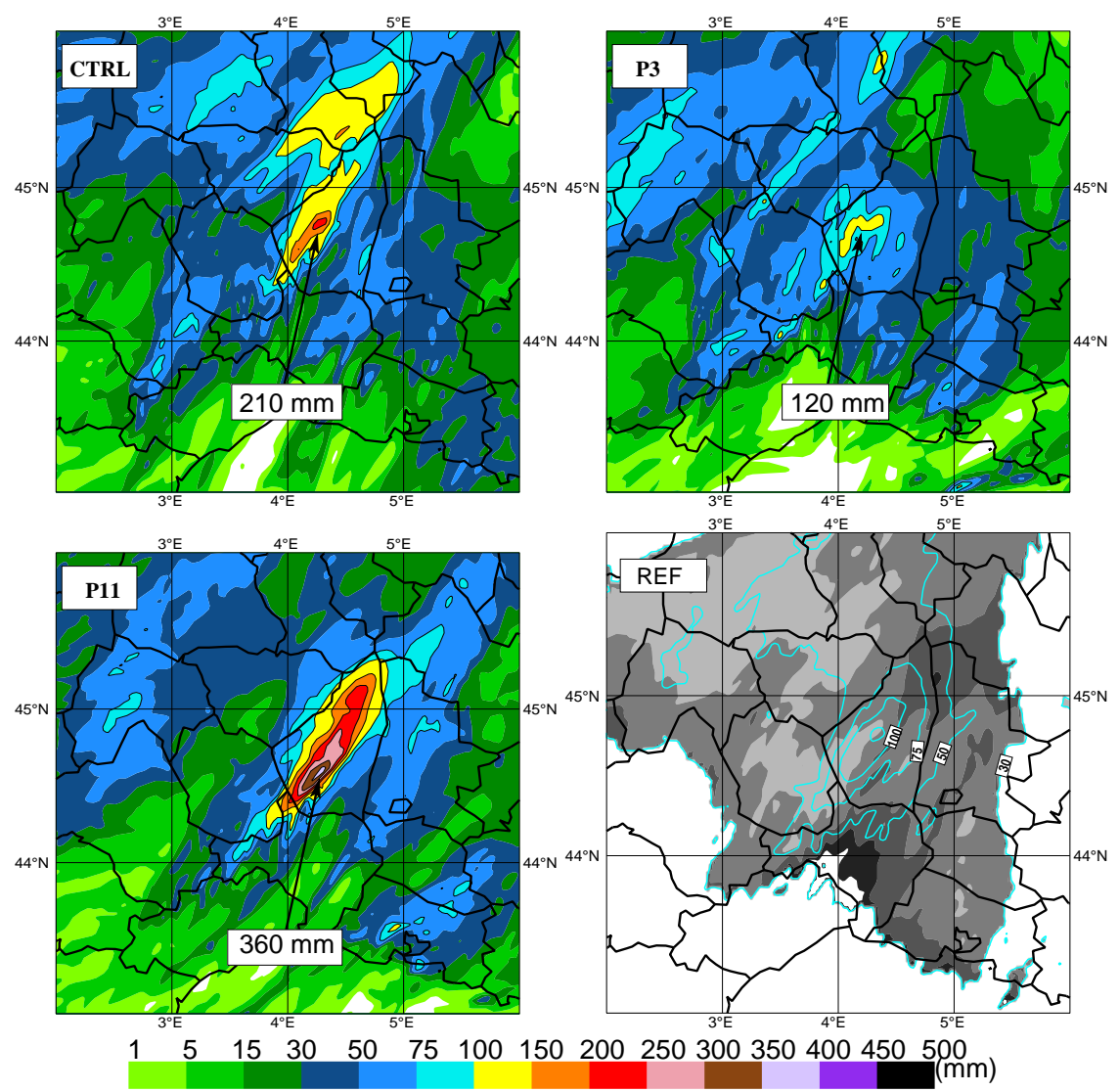

Fig. 8. Gard case 24-h accumulated simulated precipitation for the REF convective-permitting ensemble experiment. The run is valid for 8 September 2010 at 06:00 UTC and starts on 7 September 2010 at 00:00 UTC. Precipitation maxima are pointed out over the Gard department. The last panel shows the 24-h accumulated ensemble-mean (solid line) and the normalised spread (shading). The spread is not shown for precipitation below $30 \mathrm{~mm} \mathrm{day}^{-1}$.

ensemble mean accumulated precipitation and the associated normalised spread for REF. Normalised spread is not shown for precipitation ensemble mean values below $30 \mathrm{~mm}_{\text {day }}{ }^{-1}$. The Var case is characterised by moderate to strong spread with values generally around 0.6 over the Var department, and peaking near 1 over the flooded area (i.e. southeastern Var). These strong values of spread in the vicinity of the strongest precipitation ensemble mean underline that the convective system is highly unpredictable.

\subsection{The Gard-Ardèche case}

Concerning the Gard-Ardèche case, the probability for precipitation forecasts exceeding $50 \mathrm{~mm} d a y^{-1}$, valid for 8 June 2010 at 06:00 UTC and starting at 00:00 UTC on 7 September 2010 and at 18:00, 12:00 and 06:00 UTC on 6 September 2010, are displayed in Fig. 7a, b, c and d for PEARP runs. High values of probability are obtained whatever the forecast range (even for for the longest forecast range). That is a completely different result with respect to the Var case. On 6 September 2010 at 06:00 UTC, one can see in the PEARP run values of probability higher than $90 \%$ but slightly misplaced just west of the Ardèche department (Fig. 7a). In contrast to the Var event, these probabilities last and even increase with time in magnitude and also in coverage (Fig. 7b and c). On 7 September 2010 at 00:00 UTC, the area of high precipitation probabilities is largest but is still displaced westward.

Figure $7 \mathrm{e}$ and $\mathrm{f}$ shows the results for the REF ensemble experiment. Compared to PEARP, the REF ensemble yields better simulations of the precipitation event, shifting the strong probability values more over the flooded area. One can also remark that it better represents precipitation associated with the surface cold front approaching from the west.

Figure 8 shows the 24-h accumulated simulated precipitation amounts for the REF experiment. As was expected for the Gard-Ardèche case, the ensemble performs much better in terms of QPFs than it does for the Var case. Although most of the simulated precipitation amounts are still slightly underestimated, a few members are very close to observations. For instance member 11 predicts near $360 \mathrm{~mm}$ in $24 \mathrm{~h}$ in very good agreement with observations. The spread of precipitation is quite reduced with respect to the Var case and 

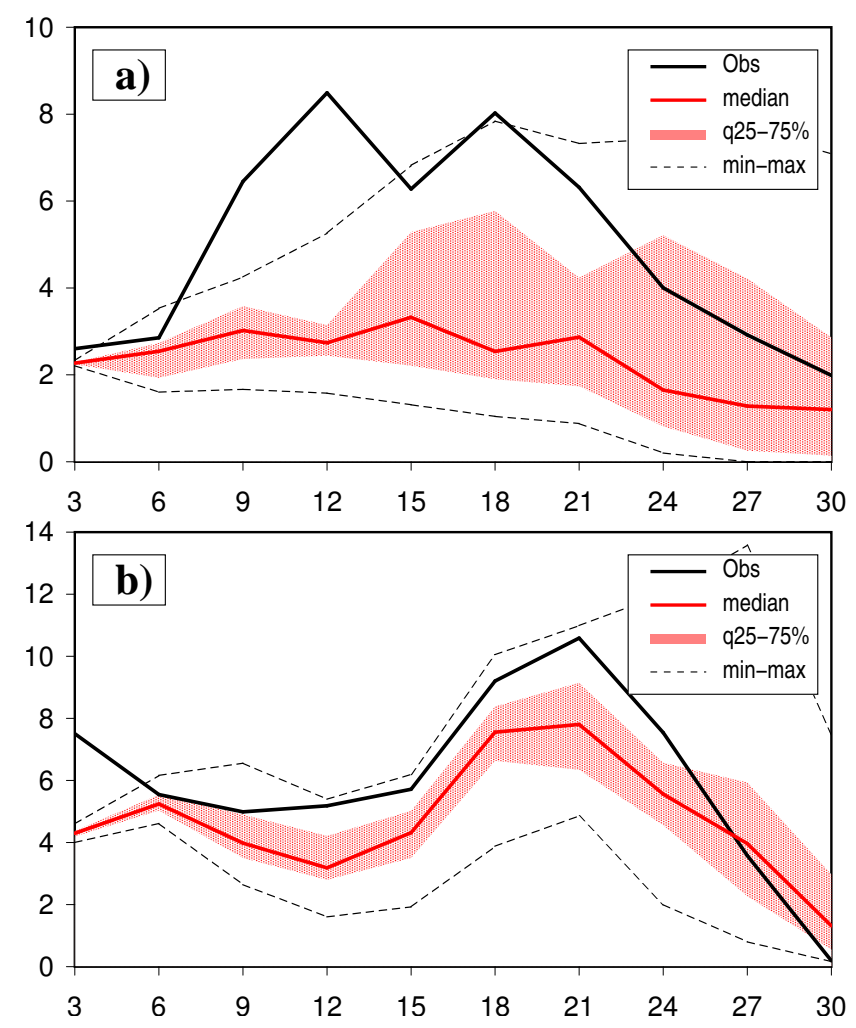

Fig. 9. Time series of the 3-h surface precipitation (mm) for REF and for the Var (a) and Gard (b) cases, averaged over the subdomain seen in Figs. 6 and 8, respectively. Interquartile ranges (25\%$75 \%$ ), minimum, maximum and medians are shown. Initial times of the forecasts are 00:00 UTC of 15 June 2010 for the Var case and 00:00 UTC of 7 September 2010 for the Gard case, respectively.

the weakest precipitation amounts are obtained for member 3 with $120 \mathrm{~mm}$.

As for the Var case, the last panel of Fig. 8 presents the 24-h ensemble mean accumulated simulated precipitation amounts and the associated normalised spread. The GardArdèche case, unlike to the Var event, is characterised by small normalised spread denoting high predictability. Normalised spread values are mainly below 0.2 over the Ardèche department and are colocalized with the strongest precipitation peak. Higher values of about 0.8 are also found in southern Gard probably in association with some scenarii in the ensemble starting convective activity earlier over the department.

\section{Discussion}

After having evaluated the REF ensemble simulation, we now emphasise the mesoscale ingredients that favoured these long-lasting HPEs and controlled their predictability. For that purpose, the ensemble-mean water vapour fluxes $\left\|q_{\mathrm{v}} \boldsymbol{V}_{\mathbf{h}}\right\|$, where $q_{\mathrm{v}}$ is the specific humidity and $\boldsymbol{V}_{\mathbf{h}}$ is the horizontal wind at $925 \mathrm{hPa}$, are shown in Fig. 10.

Afterwards, the methodology of selection is evaluated then refined using statistical predictors arising from analysis of these propitious mesoscale ingredients.

\subsection{Detailed analysis of favourable mesoscale ingredients}

In order to analyse time evolution of rainfall, Fig. 9 shows time series of simulated precipitation with maximum, minimum, median and interquartile range averaged over the subdomain seen in Fig. 2c for the Var case and Fig. 4c for the Gard-Ardèche case, respectively. The observations (bold solid line) attest the generally high skill of the ensemble median and $75 \%$ quartile for the Gard-Ardèche case (Fig. 9b), on agreement with the small values of normalised spread discussed earlier. These quantities enable to fairly capture the precipitation peak observed near 21:00 UTC on 7 September 2010. For the Var case, the ensemble median fails to reproduce the maximum for rainfall amounts and rainfall amounts are strongly underestimated. Most of ensemble scenarii fail to capture the highest precipitation over the flooded area and these results are consistent with high normalised spread noticed in Sect. 4. Nevertheless, the last quartile (i.e. $75 \%$ ) better describe time evolution of precipitation with two peaks shifted later.

An analysis of the favourable mesoscale ingredients helps to better understand the fine-scale simulated rainfall distribution from the REF ensemble. Although the averaged fields are strongly smoothed, Fig. 10a displays, at 12:00 UTC on 15 June 2010. (i.e. just before the period of heaviest rainfall for the Var case), two converging tongues of high values of water vapour flux coming from west and northwest of Sardinia. A maximum of about $100 \mathrm{~g} \mathrm{~kg}^{-1} \mathrm{~m} \mathrm{~s}^{-1}$ is found over the Mediterranean Sea and another stronger one of about $150 \mathrm{~g} \mathrm{~kg}^{-1} \mathrm{~m} \mathrm{~s}^{-1}$ over the Var department. The lowlevel horizontal winds clearly depict a surface low centered along $6^{\circ} \mathrm{E}$, strengthening the southeasterly low-level flow and thus advecting warm and moist air masses toward the French southeastern coast. At 00:00 UTC on 16 June 2010, the low moves eastwards while the low-level flow is decreasing, and the favourable environment in terms of moisture flux also shifts over Ligurian Sea. In contrast to the Var case, Fig. 10c shows values of low-level water vapour stronger than $200 \mathrm{~g} \mathrm{~kg}^{-1} \mathrm{~m} \mathrm{~s}^{-1}$. As a matter of fact, strong forcing prevails at the surface for the Gard-Ardèche case. Indeed, as the cold front moves slowly eastwards, the southerly lowlevel flow is increased ahead of the front with strong convergence over the Gulf of Lyon, bringing more moisture in to feed deep convection over the region. At 00:00 UTC on 8 September 2010, as the cold front moves further eastwards, the low-level convergence of moisture flux is displaced near the southern Alps (Fig. 10d). 


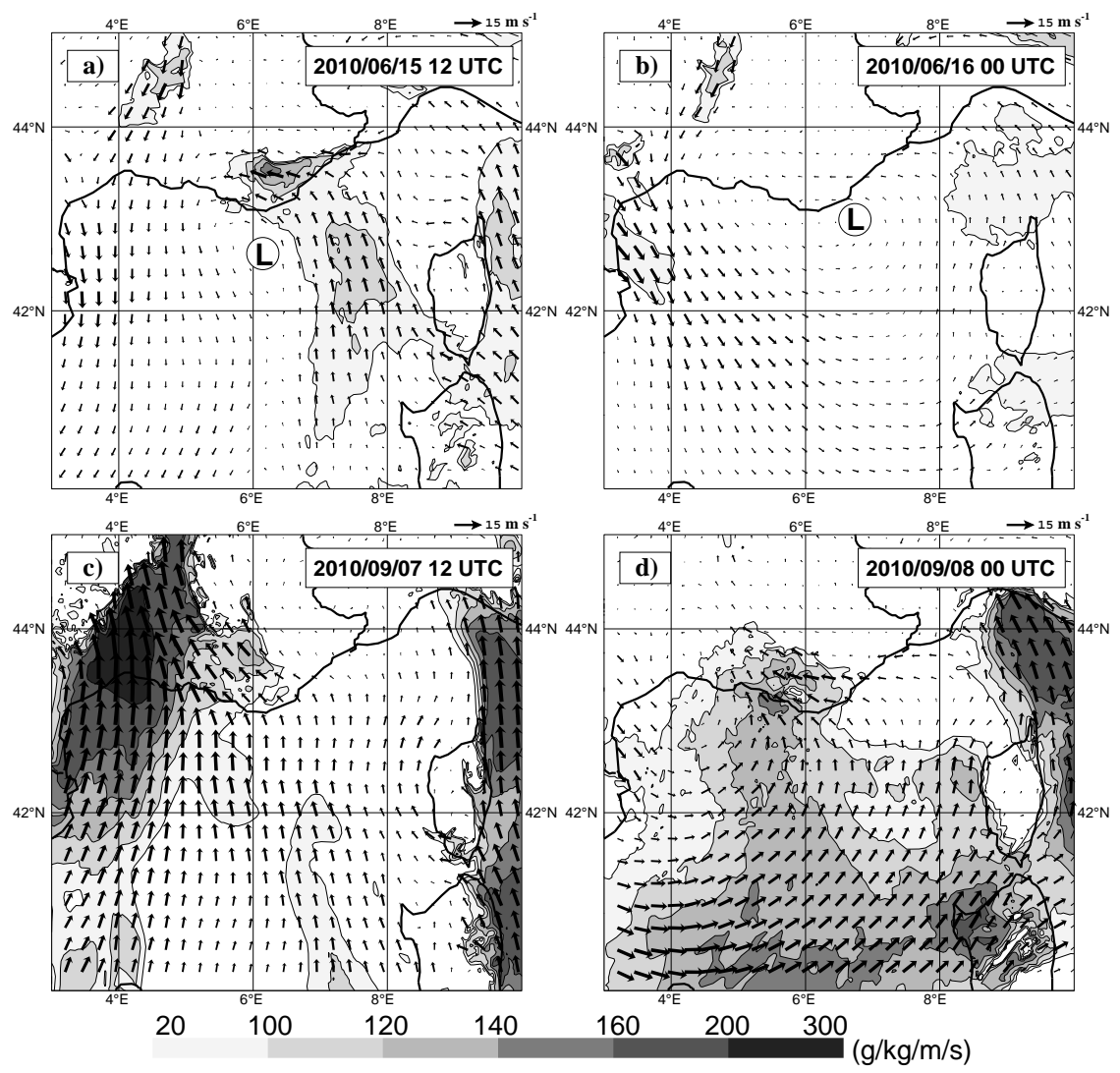

Fig. 10. 925-hPa horizontal moisture flux magnitude (shading, $\mathrm{g} \mathrm{kg}^{-1} \mathrm{~m} \mathrm{~s}^{-1}$ ) and wind vector ( $\mathrm{m} \mathrm{s}^{-1}$ ) ensemble-mean for the Var case (a and $\mathbf{b}$ ) and the Gard-Ardèche case (c and $\mathbf{d})$, respectively. Ensemble experiments shown are REF in both cases. Initial times of the forecasts are 00:00 UTC of 15 June 2010 for the Var case and 00:00 UTC of 7 September 2010 for the Gard case, respectively.

Since our study considers only uncertainty arising from synoptic scale and LBCs, the variability of high-resolution precipitation forecasts are closely related to predictability of both meteorological forcings previously discussed. In the Var case, the predictability of the surface low is very low (i.e. spread is high), and there are few members able to fairly predict the strong southeasterly low-level flow advecting the supply of moisture to sustain very intense precipitation over the Var department. This result suggests that the Var case is very sensitive to the prescribed LBCs and to their interactions with other mesoscale and convective-scale processes. Indeed, Bresson (2011) revealed that the quasi-stationary convective line over the Var region and over the Mediterranean Sea was driven primarily by a surface low over the Gulf of Lyon inducing a strong convergent low-level flow, and by convective-scale mechanisms, such as a low-level cold pool and the triggering of deep convection by small orography features. In the opposite side, the predictability of the surface cold front is higher in the Gard-Ardèche case and there is a large majority of members depicting large southerly lowlevel water vapour advection ahead of the surface front. The Gard-Ardèche case appears to have a better predictability even in PEARP and it seems to be an event more controlled by synoptic-scale conditions propagating through AROME lateral boundaries.

\subsection{Impact of selected LBCs}

In this section we investigate the sensitivity of the highresolution forecasts to different selections of LBCs from PEARP ensemble.

In a first step, we compare results obtained for subensembles in which LBCs are randomly selected against a method based on a cluster analysis. Figure 11a and b show, for the Var case, time series of 3-h simulated rainfall amounts (same as Fig. 9) and the 24-h ensemble-mean accumulated simulated precipitation (solid lines) superimposed to normalised spread (shading). For the RAND1 experiment, the evolution of the domain-averaged rainfall is slightly improved as the median indicates a peak of precipitation near 15:00 UTC on 15 June 2010. The highest quartile (i.e. $75 \%$ ) is still also showing a maximum of precipitation (Fig. 11a). However, this increase in precipitation on average is associated with higher values of normalised spread everywhere over the Var department, and the forecast uncertainty increases in the RAND1 ensemble. For the second set of 
Table 1. Var case population and RMs for the CLUST-REF, CLUSTMOIST and LAG ensembles: columns 2, 3 and 4, respectively. The clustering time is 00:00 UTC on 15 June 2010. The RMs (in parenthesis) are expressed as MMDD "p"nn, where nn indicates the perturbed element of the ensemble started on day DD. See also text for more details.

\begin{tabular}{lrrr}
\hline \multirow{2}{*}{$\begin{array}{l}\text { Cluster } \\
\text { number }\end{array}$} & \multicolumn{3}{c}{ Cluster population and RM } \\
\cline { 2 - 4 } & CLUST-REF & CLUST-MOIST & LAG \\
\hline cl 1 & $3(0615 \mathrm{p} 29)$ & $4(0615 \mathrm{p} 1)$ & $17(0615 \mathrm{p} 31)$ \\
$\mathrm{cl} 2$ & $2(0615 \mathrm{p} 30)$ & $3(0615 \mathrm{p} 30)$ & $24(0615 \mathrm{p} 26)$ \\
$\mathrm{cl} \mathrm{3}$ & $4(0615 \mathrm{p} 17)$ & $6(0615 \mathrm{p} 3)$ & $7(0614 \mathrm{p} 23)$ \\
$\mathrm{cl} 4$ & $6(0615 \mathrm{p} 20)$ & $10(0615 \mathrm{p} 32)$ & $5(0614 \mathrm{p} 31)$ \\
$\mathrm{cl} \mathrm{5}$ & $9(0615 \mathrm{p} 25)$ & $7(0615 \mathrm{p} 25)$ & $4(0614 \mathrm{p} 32)$ \\
$\mathrm{cl} \mathrm{6}$ & $8(0615 \mathrm{p} 32)$ & $2(0615 \mathrm{p} 33)$ & $8(0614 \mathrm{p} 18)$ \\
$\mathrm{cl} 7$ & $2(0615 \mathrm{p} 34)$ & $2(0615 \mathrm{p} 34)$ & $4(0614 \mathrm{p} 26)$ \\
\hline
\end{tabular}

randomly selected LBCs (RAND2 ensemble), the time series plot does better to fit observations in terms of interquartile distance mainly during the last $6 \mathrm{~h}$ of simulation. Since the forecast variability is already strong in REF for the Var case, both random experiments have very different behaviours due to the random nature of the selection of the LBCs.

As described in Sect. 3, the classification method enables to select 7 RMs out of, either the 35 elements which compose one PEARP run or the 70 that compose two successive PEARP runs. Table 1 reports cluster populations and RMs for each of the three clustering method and for the Var case. It can be noticed that, in $L A G$, the method selects members from both PEARP runs and members with different reference time also mix in some clusters. For instance, the representative member of cluster $\mathrm{cl} 3$ is selected from the $L A G$ ensemble starting on 14 June (more precisely, the perturbed element p23 is selected within a cluster with 7 elements). CLUST-REF and CLUST-MOIST ensembles both produce clusters with a comparable number of elements, except for $L A G$ in which the two populated clusters are able to gather near $60 \%$ of the total of elements. One reason for such distribution with more clusters with low populations is that the "older" run of PEARP is more confident in its results (more similar members) for the Var case, leading to more variability to be classified in $L A G$. For the Gard case, the $L A G$ has fewer clusters with low populations, whereas the two PEARP runs have more comparable variability (column 4 of Table 2).

When CLUST-REF is performed, the variability within the LBCs is thus better classified compared to random experiments, and the so-obtained sub-ensemble clearly enables to predict and focus more precipitation over the Var department in average (Fig. 11f). Two areas of strongest values of normalised spread are confined to the southwestern and southeastern part of the Var department.

When relevant meteorological parameters for the convective events of interest (i.e. geopotential height at $500 \mathrm{hPa}$ and horizontal moisture flux at $925 \mathrm{hPa}$ ) are considered (CLUST-
Table 2. Gard case population and RMs for the CLUST-REF, CLUST-MOIST and LAG ensembles: columns 2, 3 and 4, respectively. The clustering time is 00:00 UTC on 7 September 2010. The RMs (in parenthesis) are expressed as MMDD“p”nn, where nn indicates the perturbed element of the ensemble started on day DD. See also text for more details.

\begin{tabular}{lrrr}
\hline \multirow{2}{*}{$\begin{array}{l}\text { Cluster } \\
\text { number }\end{array}$} & \multicolumn{3}{c}{ Cluster population and RM } \\
\cline { 2 - 4 } & CLUST-REF & CLUST-MOIST & $L A G$ \\
\hline cl 1 & $9(0907 \mathrm{p} 17)$ & $9(0907 \mathrm{p} 17)$ & $16(0907 \mathrm{p} 17)$ \\
cl 2 & $9(0907 \mathrm{p} 18)$ & $12(0907 \mathrm{p} 18)$ & $10(0906 \mathrm{p} 4)$ \\
cl 3 & $4(0907 \mathrm{p} 5)$ & $4(0907 \mathrm{p} 5)$ & $25(0907 \mathrm{p} 18)$ \\
cl 4 & $5(0907 \mathrm{p} 6)$ & $5(0907 \mathrm{p} 6)$ & $10(0906 \mathrm{p} 23)$ \\
cl 5 & $3(0907 \mathrm{p} 28)$ & $1(0907 \mathrm{p} 14)$ & $4(0906 \mathrm{p} 5)$ \\
$\mathrm{cl} \mathrm{6}$ & $3(0907 \mathrm{p} 23)$ & $2(0907 \mathrm{p} 25)$ & $3(0906 \mathrm{p} 10)$ \\
$\mathrm{cl} \mathrm{7}$ & $1(0907 \mathrm{p} 26)$ & $1(0907 \mathrm{p} 26)$ & $1(0906 \mathrm{p} 17)$ \\
\hline
\end{tabular}

MOIST), the ensemble-mean is increased in terms of surface precipitation maximum over the flooded area (Fig. 11h). Despite a slight decrease in terms of interquartile distance in time series, CLUST-MOIST enables to better regionalise and capture the forecast uncertainty. Indeed, the strong normalised spread simulated mainly over the southeastern portion of the area clearly indicates the possible occurrence of flooding over the region of Draguignan (Fig. 11h). Furthermore, one reason for the reduction in interquartile distance could be that CLUST-MOIST leads to more variability but which is spatially more localised at the "high-impact region" due to the selection of more mesoscale parameters in the clustering.

Since it has been shown in Sect. 4 that the Var case is better predicted in the "older" PEARP runs, the cluster analysis is applied on a 70-member, lagged ensemble, joining two consecutive PEARP runs ( $L A G$ experiment). Times are 12:00 UTC on 14 June 2010 and 00:00 UTC on 15 June 2010, respectively. Figure 11g shows that the lagged-classification leads to improvement in terms of QPF, as the median is closer to observations, but the uncertainty is also increased (i.e. more normalised spread). Time series indicates more clearly the triggering time of the heaviest precipitation than any other clustering experiments. However, for $L A G$, the maximum ensemble-mean rainfall amounts are more spatially extended northwestwards over the Bouches du Rhône department with respect to CLUST-MOIST, and the forecast uncertainty strongly increases as the normalised spread also extends spatially. However, a lagged approach can nevertheless provide more useful information regarding the potential meteorological situation.

Figure 12 shows the precipitation probability maps for precipitation exceeding $50 \mathrm{~mm} / 24 \mathrm{~h}$ for the three ensembles. The impact of the selection of more relevant mesoscale ingredients is definitely noticeable for the Var case in Fig. 12b. Indeed, the probability is about $85 \%$ over the western region of the Var department for the CLUST-MOIST and the 

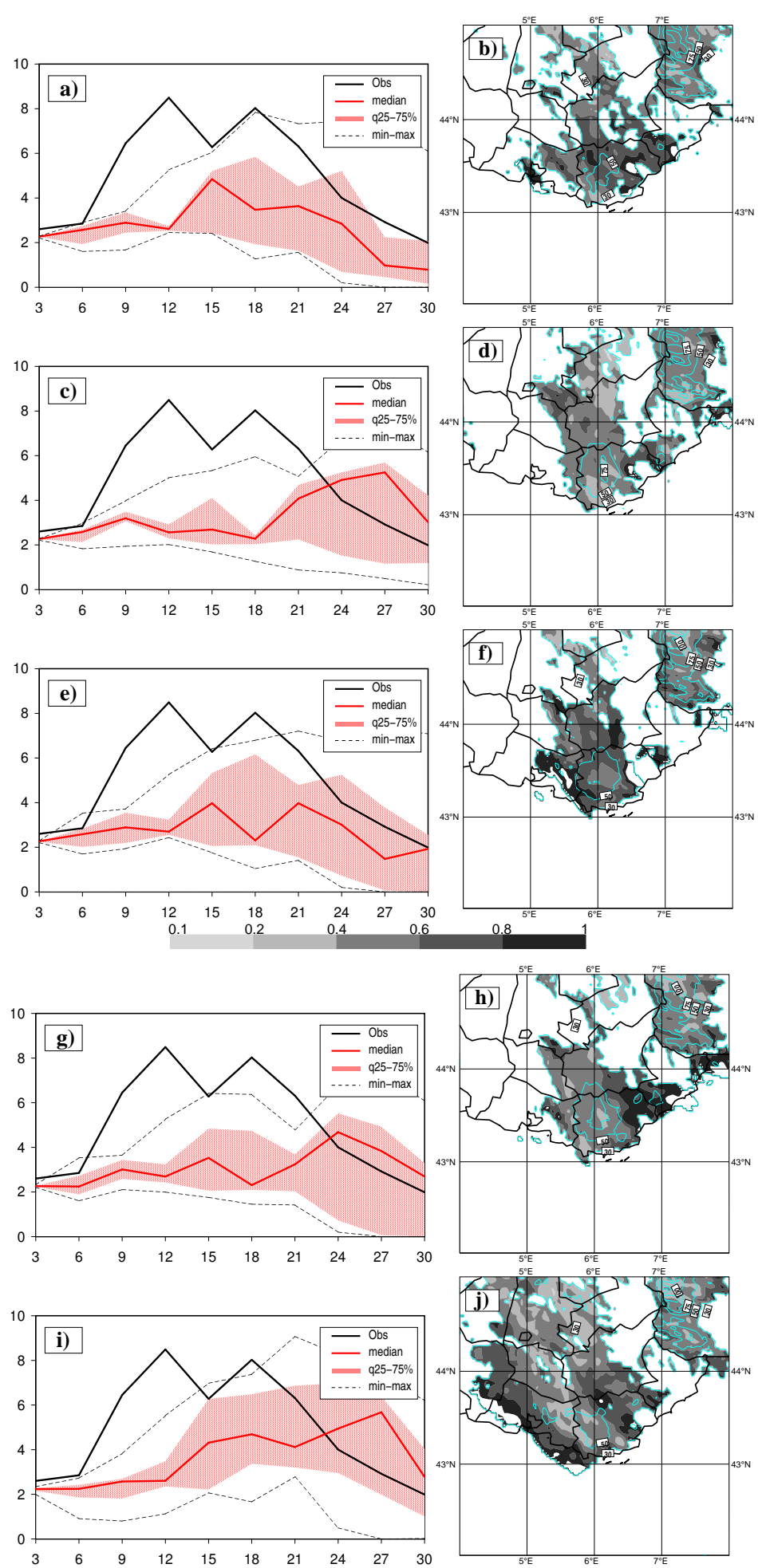

Fig. 11. Var case time series of the 3-h surface precipitation averaged over the subdomain seen in Fig. 6 and the 24-h accumulated simulated precipitation ensemble-mean (solid lines) and the normalised spread (shading) for the RAND1 (a and b), RAND2 (c and d), CLUST-REF (e and $\mathbf{f}), C L U S T-M O I S T$ ( $\mathbf{g}$ and $\mathbf{h}$ ), and $L A G$ (i and $\mathbf{j})$ ensemble experiments. Interquartile ranges $(25 \%-75 \%)$, minimum, maximum and medians are shown. The accumulation 24-h period starts on 15 June 2010 at 00:00 UTC and ends on 16 June 2010 at 06:00 UTC. 

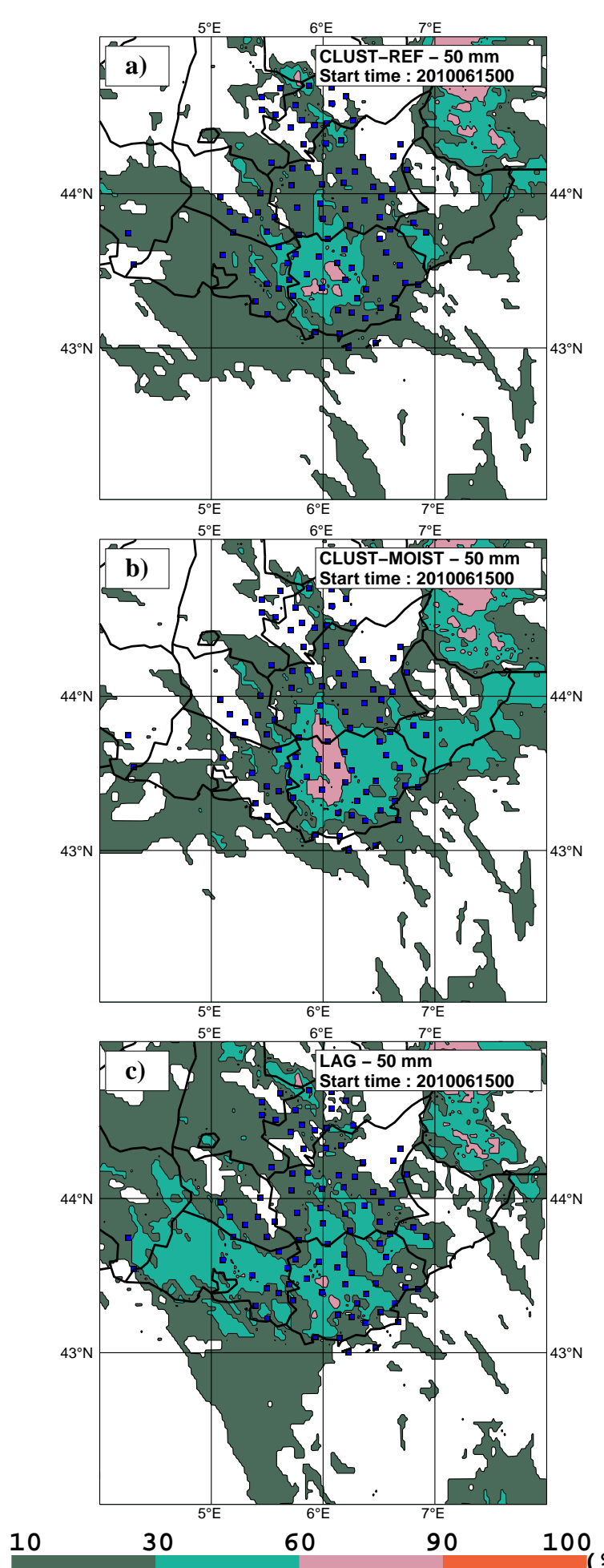

Fig. 12. Var case probability map for the 24-h accumulated precipitation (valid at 06:00 UTC on 16 June 2010) exceeding $50 \mathrm{~mm}$ and for (a) CLUST-REF, (b) CLUST-MOIST and (d) LAG. The squares are observations (rain-gauges) over the same threshold.

probability values are generally increased everywhere over Var compared to CLUST-REF. As for $L A G$, probability values are generally higher than CLUST-REF but they are more spatial extended, probably related to more spread in $L A G$.

The same sensitivity experiments are carried out for the Gard-Ardèche case (Fig. 13). For both RAND1 and RAND2 ensemble experiments, the spatial distributions of normalised spread are close except for a narrow band of high values of spread of about 0.8 oriented southwest-northeast through the Ardèche department in RAND2 (Fig. 13b and d). Both series have virtually the same departure to observations (Fig. 13a and c). Both selections from cluster analysis (CLUST-REF and CLUST-MOIST) indicate a large decrease of the normalised spread and strong values of rainfall amounts over the southwestern part of the department. This implies that both ensembles become more confident as the forecast variability decreases. However, there are still high values of spread west and south of the flooded area associated with some scenarii in the ensemble starting convective activity earlier on 6 September 2010 over the Gard department, and the surface cold front approaching, respectively. When two successive PEARP runs are combined (12:00 UTC on 6 September 2010 and 00:00 UTC on 7 September 2010), the median of the reduced ensemble after the selection is closer to observations and the interquartile distance is fairly increased, again as both PEARP runs have more comparable variability. The spatial distribution of normalised spread is generally the same except for stronger uncertainty northeast of the Ardèche department. In terms of rainfall probability charts, there is much less difference between clustering methods compared to the Var case. The Gard event is well predicted whatever the clustering selection approach (Fig. 14).

It is worth noticing that our C-P ensembles have also to be assessed over longer periods but our results are similar to those obtained by Montani et al. (2003); Marsigli et al. (2005); Montani et al. (2011). They confirm that, although the skill of the most recent ensemble forecasts is better than that of older ensembles and of the whole joined-ensemble, mixing successive global EPS runs provides, especially for some case with low predictability, higher quality probabilistic forecasts since the joined-ensemble enable to better explore regions of the phase-space of the system otherwise left unexplored by the most recent global ensemble.

\section{Synthesis and concluding remarks}

In this study a methodology of selection of lateral boundary conditions (LBCs) was presented. This approach is dedicated for convection-permitting (C-P) ensemble simulations of heavy precipitation events.

A first reference C-P ensemble was carried out with the AROME model, using the ARPEGE Ensemble Prediction System (PEARP) members as LBCs (REF experiment). In this reference ensemble, the 35 members start from a unique 

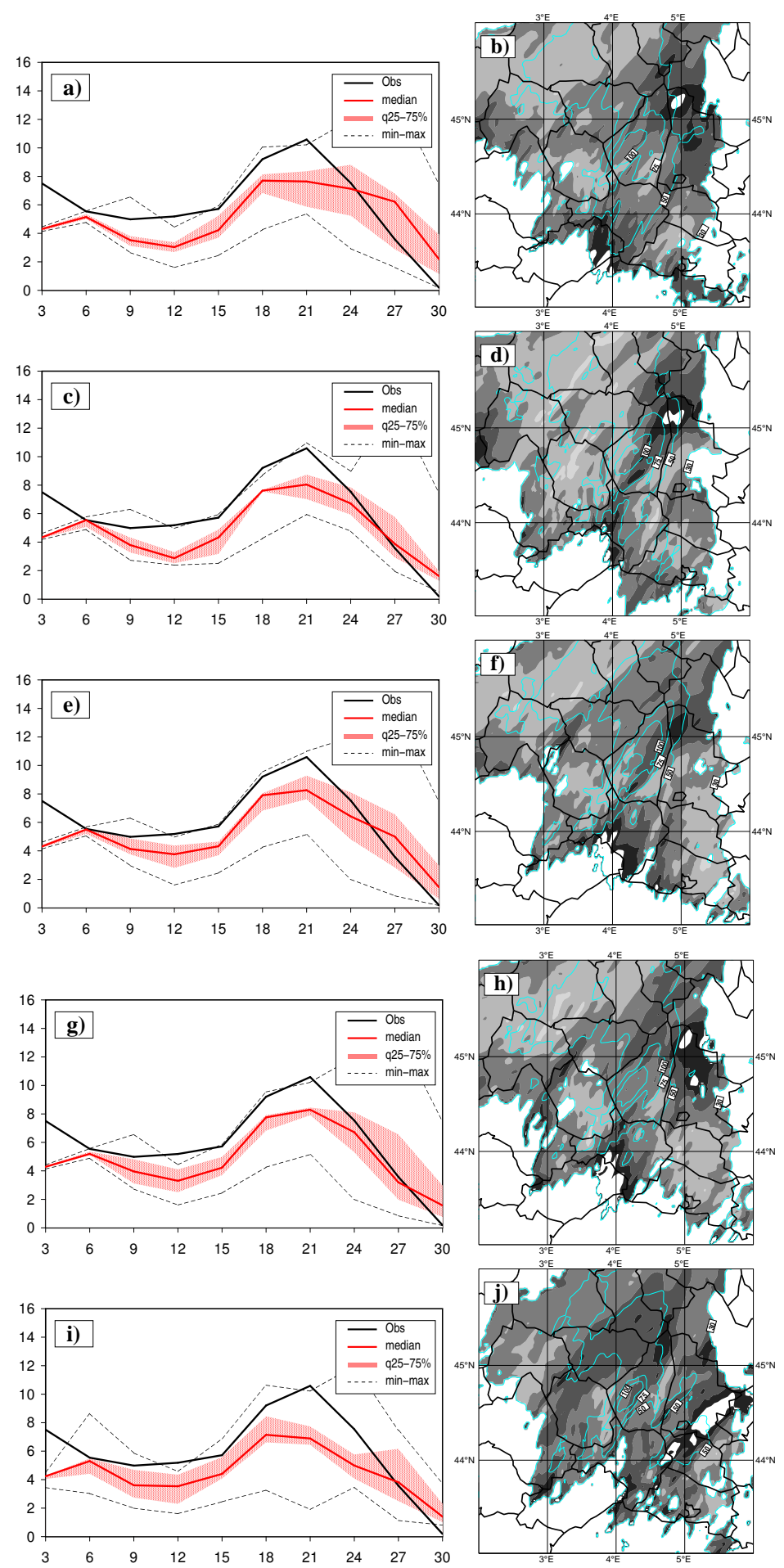

Fig. 13. Gard case time series of the 3-h surface precipitation averaged over the subdomain seen in Fig. 8 and the 24-h accumulated simulated precipitation ensemble-mean (solid lines) and the normalised spread (shading) for the RAND1 (a and b), RAND2 (c and d), CLUST-REF (e and f), CLUST-MOIST ( $\mathbf{g}$ and $\mathbf{h}$ ), and LAG (i and $\mathbf{j}$ ) ensemble experiments. Interquartile ranges (25\%-75\%), minimum, maximum and medians are shown. The accumulation 24-h period starts on 7 September 2010 at 00:00 UTC and ends on 8 September 2010 at 06:00 UTC. 

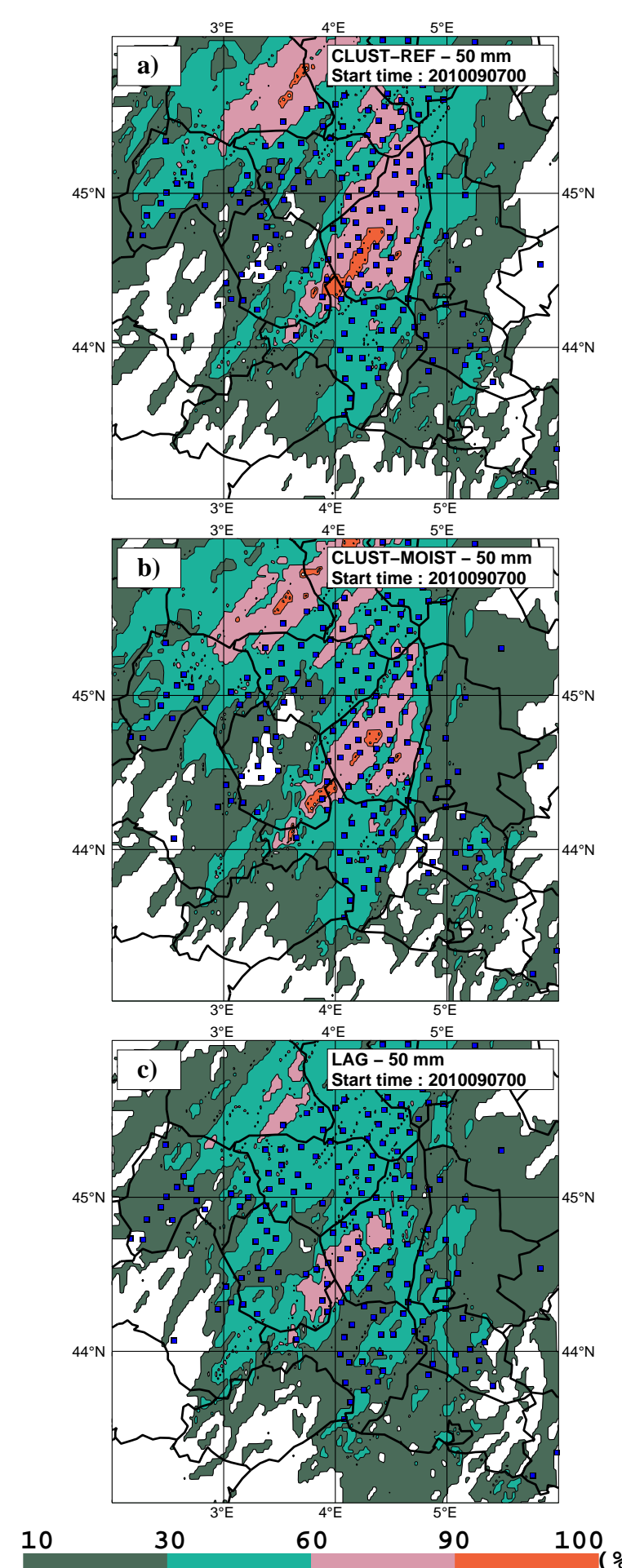

Fig. 14. Gard case probability map for the 24-h accumulated precipitation (valid at 06:00 UTC on 8 September 2010) exceeding $50 \mathrm{~mm}$ and for: (a) CLUST-REF, (b) CLUST-MOIST and (d) LAG. The squares are observations (rain-gauges) over the same threshold.

initial condition provided by a parallel mesoscale data assimilation performed over the AROME domain in order to get the best initial state as possible. They were also driven by the 35 PEARP members. The REF ensemble was used to assess the predictability of two cases of Mediterranean heavy precipitation events.

A comparison between PEARP and REF was performed. For that purpose, both ensembles were aggregated over boxes of $0.2 \times 0.2^{\circ}$. Predictability was found very different for both case studies. It has been found that the Gard-Ardèche case is more predictable even at PEARP horizontal resolution. Indeed, high values of probability exceeding $50 \mathrm{~mm} \mathrm{day}^{-1}$ of about $90 \%$ were obtained over Ardèche, whatever the time of the PEARP runs. On the other hand, for the Var case, high values of probability were not found at the time closest to the event, but for the longest forecast ranges. Probabilities of about $40 \%$ are located over the northeastern and southwestern part of the Var department on 14 June 2010 at 06:00 UTC, but strongly decreased at 00:00 UTC on 15 June 2010. The predictability of the Var case was highly increased in the C$\mathrm{P}$ ensemble, and the REF ensemble performed better than PEARP. The fine-scale variability of precipitation is closely controlled by the precise location of a quasi-stationary convective line over the Var region and over the Mediterranean Sea. This convective line was driven primarily by a surface low over the Gulf of Lyon inducing a strong convergent lowlevel flow, and accordingly advecting strong moisture supply from the Mediterranean Sea toward the flooded area.

In the Gard-Ardèche case, the differences between PEARP and REF were less significant. Indeed, in the former case, a surface cold front moved slowly eastwards while increasing the low-level water vapour ahead. These meteorological forcings were already well predictable in PEARP. Nevertheless, thanks to a better description of fine-scale orography in AROME, the REF ensemble succeeded in replacing correctly the precipitation maximum over the flooded-area.

If carrying out such a 35-member size C-P ensemble is easier for research studies, such a running appears less conceivable in an operational framework. A methodology of selection dedicated for C-P ensemble simulations of heavy precipitation events was evaluated. Consequently, the initial size of the reference ensemble is reduced down to 8 members, either randomly selecting 7 LBCs from PEARP members or isolating 7 LBCs from a cluster analysis on PEARP members. The selection based on a cluster analysis of the PEARP members (CLUST-REF) generally better performs against a random selection. The consideration of relevant meteorological parameters for the convective events of interest (i.e. geopotential height at $500 \mathrm{hPa}$ and horizontal moisture flux at $925 \mathrm{hPa}$ ) refined the cluster analysis (CLUST-MOIST). It also helped in better capturing the forecast uncertainty variability which is spatially more localised at the "high-impact region" due to the selection of more mesoscale parameters. In $L A G$, the method selects members from both PEARP runs and members with different reference time also mix in some 
clusters. Although there is a strong increase in forecast uncertainty, a lagged approach can provide more useful probabilistic information regarding the potential meteorological situation.

In this study, uncertainty sources arising from LBCs have been taken into consideration. However, it has been also found a strong sensitivity to mesoscale initial conditions in the REF experiment. Indeed, we carried out an additional sensitivity experiment $(A D A P)$ not discussed in the present paper, in which each ensemble member used, as mesoscale initial state, one of the PEARP members that is basically interpolated from its native horizontal resolution (of about $15 \mathrm{~km}$ over France) toward $2.5 \mathrm{~km}$. LBCs were also provided by the retained PEARP member. The results revealed that the REF ensemble better performed than $A D A P$, especially for the less predictable case (i.e. the Var case). For the GardArdèche case, both REF and ADAP were still close since the surface cold front moving slowly eastwards was already well represented in PEARP. A partial conclusion would be that a simple downscaling of global EPS members can be sufficient, in some cases, to sample a large part of the C-P forecast errors.

Nevertheless, the design of a future C-P ensemble will need to combine all the major uncertainty sources and the sampling approach for the AROME mesoscale initial condition uncertainties is a work in progress. An ensemble data assimilation was already evaluated for two Mediterranean heavy precipitation case studies (Vié et al., 2011). Moreover, a stochastic physics scheme (adaptated from ECMWF's stochastic perturbation physics tendencies) is currently assessed in the AROME short-range C-P ensemble prediction system (Bouttier et al., 2012). A more systematic evaluation, calculating probabilistic score over longer periods, is needed to validate our results obtained for two heavy precipitation case studies. These scientific issues will be reported in forthcoming publications.

Acknowledgements. This work was carried out in the framework of the MEDUP project (grant ANR-07-315 VULN-06-001), funded by the Vulnerabilite Milieux et Climat (VMC) programme of ANR. We gratefully acknowledge the comments made by the anonymous reviewers that helped to significantly improve the quality of the paper.

Edited by: D. Lambert

Reviewed by: two anonymous referees

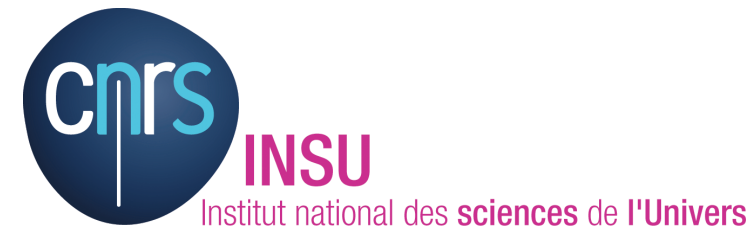

The publication of this article is financed by CNRS-INSU.

\section{References}

Bénard, P.: On the use of a wider class of linear systems for the design of constantcoefficients semi-implicit time schemes in NWP, Mon. Weather Rev., 132, 1319-1324, 2004.

Bouttier, F., Vié, B., Nuissier, O., and Raynaud, L.: Impact of stochatic physics in a convection-permitting ensemble, Mon. Weather Rev., doi:10.1175/MWR-D-12-00031.1, 2012.

Bresson, E.: Mécanismes de formation des systèmes convectifs quasi-stationnaires en Méditerranée nord-occidentale, Application au cas du 15 Juin 2010 sur le Var, Ph.D. thesis, Université Toulouse III Paul Sabatier, 2011.

Bresson, R., Ricard, D., and Ducrocq, V.: Idealized mesoscale numerical study of Mediterranean heavy precipitating convective systems, Meteor. Atmos. Phys., 103, 45-56, 2009.

Bubnova, R., Hello, G., Bénard, P., and Geleyn, J.-F.: Integration of the fully elastic equations cast in the hydrostatic pressure terrainfollowing coordinate in the framework of the ARPEGE/Aladin NWP system, Mon. Weather Rev., 123, 515-535, 1995.

Caniaux, G., Redelsperger, J.-L., and Lafore, J.-P.: A numerical study of the stratiform region of a fast-moving squall line. 1. general description and water and heat budgets, J. Atmos. Sci., 51, 2046-2074, 1994.

Chancibault, K., Anquetin, S., Ducrocq, V., and Saulnier, G.-M.: Hydrological evaluation of high-resolution precipitation forecasts of the Gard flash-flood event (8-9 September 2002), Q. J. Roy. Meteor. Soc., 132, 1091-1117, 2006.

Cuxart, J., Bougeault, P., and Redelsperger, J.-L.: A turbulence scheme allowing for mesoscale and large-eddy simulations, Q. J. Roy. Meteorol. Soc., 126, 1-30, 2000.

Ducrocq, V., Nuissier, O., Ricard, D., Lebeaupin, C., and Thouvenin, T.: A numerical study of three catastrophic precipitatating events over southern France, II: Mesoscale triggering and stationarity factors, Q. J. Roy. Meteor. Soc., 134, 131-145, 2008.

Federico, S., Avolio, E., Bellecci, C., Lavagnini, A., and Walko, R. L.: Predictability of intense rain storms in the Central Mediterraneanbasin: sensitivity to upper-level forcing, Adv. Geosci., 12, 5-18, doi:10.5194/adgeo-12-5-2007, 2007.

Fritsch, J. and Carbone, R.: Improving quantitative precipitation forecasts in the warm season: a USWRP research and development strategy., B. Am. Meteor. Soc., 85, 955-965, 2004.

Gebhardt, C., Theis, S., Paulat, M., and Ben Bouallègue, Z.: Uncertainties in COSMO-DE precipitation forecasts introduced by model perturbations and variation of lateral boundaries, Atmos. Res., 100, 168-177, 2011.

Grimit, E. and Mass, C.: Initial results of a mesoscale shortrange ensemble forecasting system over the Pacific North-West, Weather Forecast., 17, 192-205, 2002.

Hohenegger, C. and Schär, C.: Predictability and error growth dynamics in cloud-resolving models, J. Atmos. Sci., 64, 4467- 
4478, 2007.

Hohenegger, C., Lüthi, D., and Schär, C.: Predictability mysteries in cloud-resolving models, Mon. Weather Rev., 134, 2095-2107, 2006.

Kong, F., Xue, M., Droegemeier, K., Bright, D., Coniglio, M., Thomas, K., Wang, Y., Weber, D., Kain, J., Weiss, S., and Du, J.: Preliminary analysis on the real-time storm-scale ensemble forecasts produced as part of the NOAA hazardous weather testbed 2007 spring experiment, in: 22nd Conf. on Weather Analysis and Forecasting/18th Conf. on Numerical Weather Prediction, Amer. Meteor. Soc., vol 3B.2, available at: http://ams.confex.com/ams/ 22WAF18NWP/techprogram/paper_124667\%.htm, 2007.

Lafore, J. P., Stein, J., Asencio, N., Bougeault, P., Ducrocq, V., Duron, J., Fischer, C., Héreil, P., Mascart, P., Masson, V., Pinty, J. P., Redelsperger, J. L., Richard, E., and Vilà-Guerau de Arellano, J.: The Meso-NH Atmospheric Simulation System. Part I: adiabatic formulation and control simulations, Ann. Geophys., 16, 90-109, doi:10.1007/s00585-997-0090-6, 1998. .

Marsigli, C., Montani, A., Nerozzi, F., Paccagnella, T., Tibaldi, S., Molteni, F., and Buizza, R.: A strategy for high resolution ensemble prediction, II: Limited-area experiments in four Alpine flood events, Q. J. Roy. Meteor. Soc., 127, 2095-2115, 2001.

Marsigli, C., Boccanera, F., Montani, A., and Paccagnella, T.: The COSMO-LEPS mesoscale ensemble system: validation of the methodology and verification, Nonlin. Processes Geophys., 12, 527-536, doi:10.5194/npg-12-527-2005, 2005.

Mass, C., Ovens, D., Westrick, K., and Colle, B.: Does increasing horizontal resolution produce more skillful forecasts?, B. Am. Meteor. Soc., 83, 407-430, 2002.

Molteni, F. and Palmer, T.: Predictability and finite time instability of the northern winter circulation, Q. J. Roy. Meteor. Soc., 119, 269-298, 1993.

Molteni, F., Buizza, F., Palmer, T., and T., and Petroliagis, T.: The ECMWF ensemble prediction system: Methodology and validation, Q. J. Roy. Meteor. Soc., 122, 73-119, 1996.

Molteni, F., Buizza, R., Marsigli, C., Montani, A., Nerozzi, F., and Paccagnella, T.: A strategy for high resolution ensemble prediction. I: Definition of representative numbers and global-model experiments, Q. J. Roy. Meteor. Soc., 127, 2069-2094, 2001.

Montani, A., Marsigli, C., Nerozzi, F., Paccagnella, T., Tibaldi, S., and Buizza, R.: The Soverato flood in Southern Italy: performance of global and limited-area ensemble forecasts, Nonlin. Processes Geophys., 10, 261-274, doi:10.5194/npg-10-2612003, 2003.

Montani, A., Cesari, D., Marsigli, C., and Paccagnella, T.: Seven years of activity in the field of mesoscale ensemble forecasting by the COSMO-LEPS system: main achievements and open challenges, Tellus A, 63, 605-624, 2011.

Nuissier, O., Ducrocq, V., Ricard, D., Lebeaupin, C., and Anquetin, S.: A numerical study of three catastrophic precipitating events over southern France, I: Numerical framework and synoptic ingredients, Q. J. Roy. Meteor. Soc., 134, 111-130, 2008.
Nuissier, O., Joly, B., Joly, A., Ducrocq, V., and Arbogast, P.: A statistical downscaling to identify the large-scale circulation patterns associated with heavy precipitation events over southern France, Q. J. Roy. Meteor. Soc., 137, 1812-1827, 2011.

Nutter, P., Stensrud, D., and Xue, M.: Effects of coarsely resolved and temporally interpolated lateral boundary conditions on the dispersion of limted-area ensemble forecasts, Mon. Weather Rev., 132, 2358-2377, 2004.

Pergaud, J., Masson, V., and Malardel, S.: A parameterization of dry thermals and shallow cumuli for mesoscale numerical weather prediction, Bound.-Lay. Meteorol., 132, 83-106, 2009.

Richard, E., Cosma, S., Tabary, P., Pinty, J.-P., and Hagen, M.: Highresolution numerical simulations of the convective system observed in the Lago Maggiore area on 17 September 1999 (MAP IOP 2a), Q. J. Roy. Meteor. Soc., 129, 543-564, 2003.

Seity, Y., Brousseau, P., Malardel, S., Hello, G., Bénard, P., Bouttier, F., Lac, C., and Masson, V.: The AROME-France convective scale operational model, Mon. Weather Rev., 139, 976-991, 2011.

Stein, J., Richard, E., Lafore, J.-P., Pinty, J.-P., Asencio, N., and Cosma, S.: High-resolution non-hydrostatic simulations of flashflood episodes with grid-nesting and ice phase, Meteor. Atmos. Phys., 72, 203-221, 2000.

Stensrud, D., Bao, J., and Warner, T.: Using initial conditions and model physics in short-range ensemble simulations of mesoscale convective systems, Mon. Weather Rev., 128, 2077-2107, 2000.

Toth, Z. and Kalnay, E.: Ensemble forecasting at NCEP and the breeding method, Mon. Weather Rev., 125, 3297-3319, 1997.

Vié, B., Nuissier, O., and Ducrocq, V.: Cloud-resolving ensemble simulations of mediterranean heavy precipitating events: uncertainty on initial conditions and lateral boundary conditions, Mon. Weather Rev., 139, 403-423, 2011.

Vincendon, B., Ducrocq, V., Saulnier, G., Bouilloud, L., Chancibault, K., Habets, F., and Noilhan, J.: Benefit of coupling the ISBA land surface model with a TOPMODEL hydrological model dedicated to Mediterranean flash floods, J. Hydrol., 11, 1529-1544, 2010.

Walser, A., Lüthi, D., and Schär, C.: Predictability of precipitation in a cloud-resolving model, Mon. Weather Rev., 132, 560-577, 2004.

Zappa, M., Beven, K., Bruen, M., Cofino, A., Kok, K., Martin, E., Nurmi, P., Orfila, B., Roulin, E., Schroter, K., Seed, A., Szturc, J., Vehvilainen, B. Germann, U., and Rossa, A.: Propagation of uncertainty from observing systems and NWP into hydrological models: COST-731 working group 2, Atmos. Sci. Lett., 11, 8391, 2010.

Zhang, F., Meng, Z., and Aksoy, A.: Tests of an ensemble Kalman filter for mesoscale and regional-scale data assimilation, Part I: perfect model experiments, Mon. Weather Rev., 134, 722-736, 2006. 